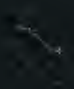




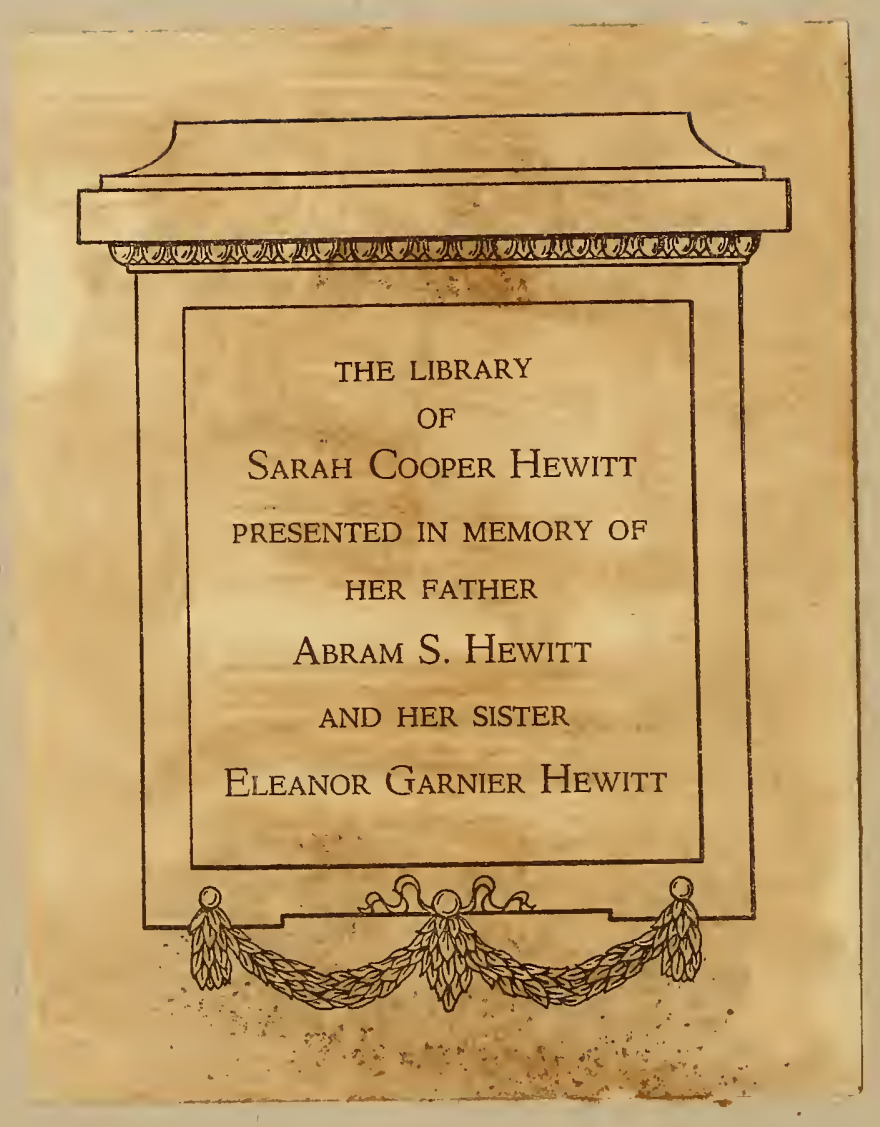










ct Momizun Metinarn

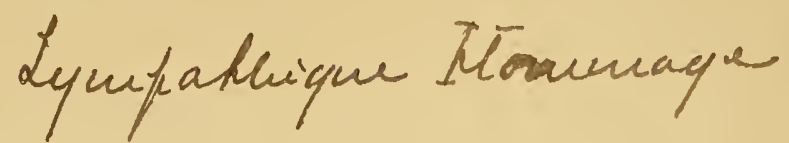
Etequer?

\section{GASPARD GREGOIRE}

ET SES

VELOURS D'ART 




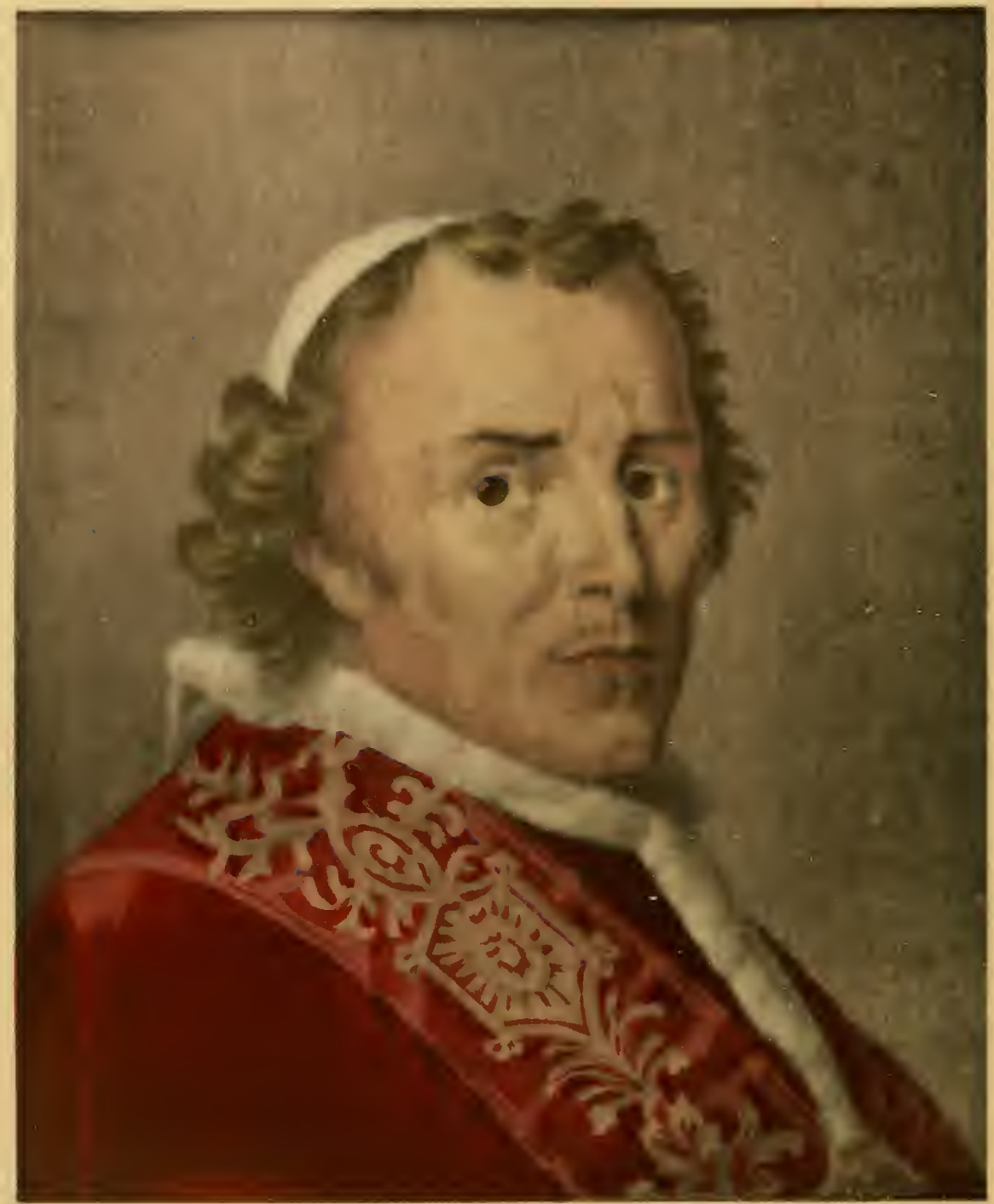

Plototypie Berthaud

Portrait de Pie V'II

Musée des Arts Décoratifs 


\section{MENRI ALGOUD}

\section{GASPARD GRÉGOIRE}

ET SES

\section{VELOURS D'ART}

\section{PARIS}

SOCIÉTE FRANÇAISE D'IMPRIMERIE ET DE LIBRAIRIE ANCIENNB LIBRAIRIE LECÈNE, OUDIN BT cie

15, Rue de Clung, 15

1908

Droits de reproduction ei de traduction réservés pour tous les pays. 


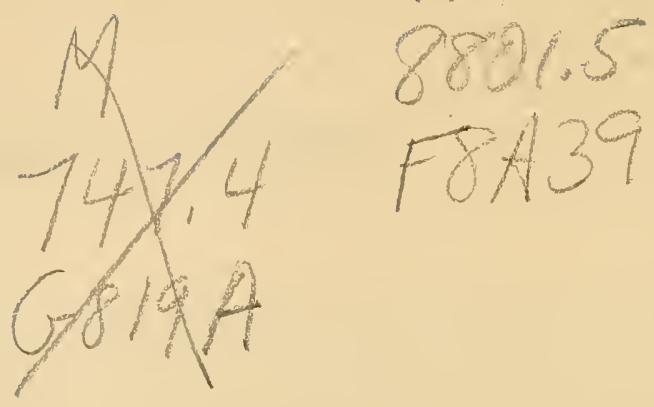

$: 128909: 2$

MAR 1595 Coper Union Library 
Il nous est très agréable de dire ici que nombre d'indications précieuses pour ce travail nous ont été fournies fort obligeamment par Mr. Maurice Raimbault, des Archives des Bouchesdu-Rhòne; nous sommes redevables également à Mr. Montagne de Firmont, d'Aix, de renseignements très utiles, de mème qu'à Mr. T. Martel, de Lyon. Enfin tout ce qui concerne la partie si délicate des recherches dans les bibliothèques et archives à Paris, a été assumé par Mr. Henri Zaleski, avec un zèle averti et un dévouement qui nous font estimer son aide, ainsi qu'elle doit l'ètre, c'est-à-dire comme une véritable collaboration.

H. A. 



\section{GaSPARD GRÉG0IRE}

ET SES

\section{VELOURS D'ART}

L'organisation d'une section rétrospective à l'Exposition en 1906 au Musée Galliera, de " la Soie, ses applications, son décor ", fut l'occasion d'y réserver une place à plusieurs spécimens de Velours Grégoire, ou Velours de soie, peints.

Connues des amateurs et des spécialistes, à peu près ignorées du grand public, ces intéressantes productions, portraits ou sujets, toujours de proportions petites, apparaissent par leur dessin très sûr, leur coloris délicat et parfaitement fondu, comme un genre de miniature, si l'on peut s'exprimer ainsi, tout spécial et d'un incontestable mérite artistique. Devant ces œuvres, - et cette opinion du premier abord est la plus commune, - on serait tenté de croire que leur caractère résulte simplement de l'effet d'une peinture exécutée sur un velours et empruntantà ce support soyeux son aspect particulier, mat, estompé et cependant net. Il n'en est rien toutefois : ces peintures n'ont pas été faites sur le velours tissé, sur l'étoffe toute terminée, mais bien sur les fils de soie mêmes, qui ont servi " après " à fabriquer ce velours ; procédé bien difficile et compliqué, dira-t-on. Il a fallu toute l'idée ingénieuse de Grégoire pour le concevoir, tout son travail patient, opiniâtre, pour le mettre à exécution et en arriver au tour de main resté son secret, car ses imitateurs n'ont pas atteint à beaucoup près les mêmes résultats. 
Avant Grégoire, et depuis longtemps, on savait façonner le velours de dessins, de broderies, et des plus riches; ón avait aussi essayé avec succès d'user, pour décorer cette étoffe, du procédé du "Chinage à la Branche " qu'on voit utilisé sur de nombreux taffetas et satins $d u x^{x}{ }^{2}{ }^{\mathrm{e}}$, procédé assez inexpliqué de nos jours, qu'on peut dire perdu même, et duquel sans doute Grégoire s'est inspiré pour créer le sien, mais ce fut bien une création que cette décoration nouvelle, - à la main, - appliquée à une étoffe de soie, et qui fit sensation à l'époque où elle fut mise au jour.

Passionné longtemps pour sa nouveauté, si bien réussie en petit et pour une production limitée, ayant passé des années à des recherches d'exécution qui ne lui ménagèrent ni les difficultés, ni les déboires et les découragements qui attendent toul novaleur, il crut cependant à un moment avoir triomphé de toul et ètre en possession d'une branche inédite de l'Art de la décoration de l'étoffe, possible presque industriellement. Son espoir jusque-là fut déçu el aussi sans doute son rêve de fortune, car il eut la malchance encore de vivre à une époque trop troublée par les agitations politiques.

En tous les cas, nous devons à ses persévérants efforts ce qu'il ne nous semble pas exagéré d'appeler de petits chefsd'œuvre. C'est à la description de ceux de ces velours " d'art " qu'il nous a été donné de connaitre, à ce qu'on a pu savoir et reconstituer des procédés de Grégoire, à des détails biographiques inédits, croyons-nous, sur lui-même, que nous avons la pensée, peut-être la prétention, de consacrer cette ètude. 

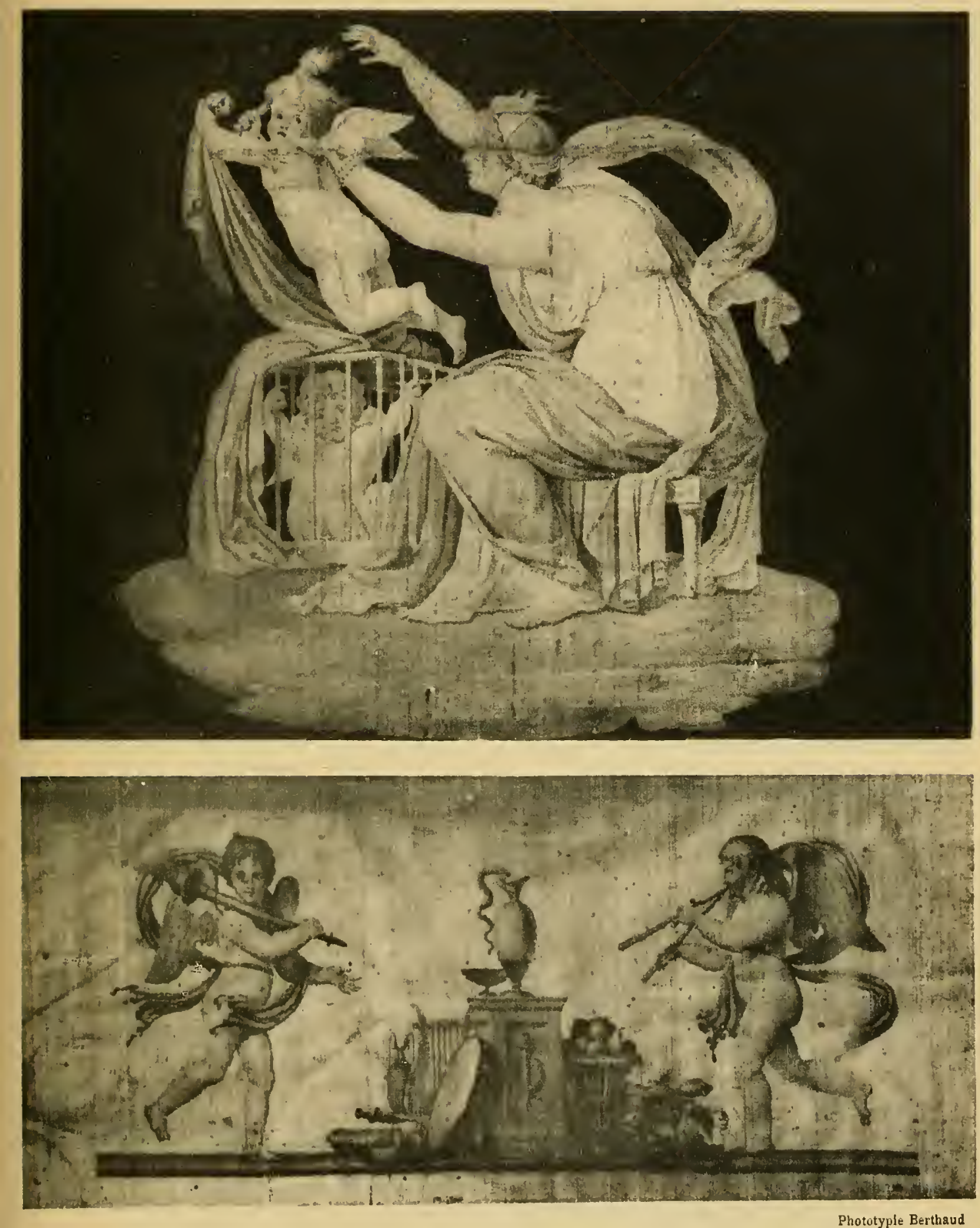

La Marchande D'Amours

(D’aprés l'exemplaire du Musée Historique des Tissus de Lyon). 



\section{NOTES BIOGRAPHIQUES}

Et d'abord, qui était Grégoire?

L'auteur d'un travail sur l'Exposition de l'Union centrale des Arts décoratifs, en 1880, $\mathrm{M}^{\mathrm{r}}$ Gaston. Lebreton, dit dans les lignes qu'il consacre aux tissus peints:

"Il nous reste à parler des tissus peints et imprimés : un " artiste de Lyon de la fin du $\mathrm{xv}^{\mathrm{e}}{ }^{\mathrm{e}}$ acquit une réputation " pour ses velours peints; nous voulons parler de Grégoire, " dont le Musée industriel de Lyon a exposé plusieurs " œuvres fort curieuses. "

Havard, dans son dictionnaire si remarquable de l'Amellblement et de la Décoration, parle des relours Grégoire, sans donner ancun détail sur leur auteur.

Dans le Dictionnaire des Tissus, de Bezon, ouvrage technique, il est fait mention des velours imitant la peinture de "Mr Grégoire, de Paris ».

Dans d'autres ouvrages spéciaux, notamment le Catalogue des Collections du Musée historique des Tissus de Lyon, nous n'avons trouvé aucune note biographique.

Il peut paraître tout naturel et plausible de faire vivre et travailler à Lyon l'inventeur d'un procédé s'appliquant à une étoffe de soie. alors que la fabrication de ces tissus était, pour ainsi dire, monopolisée au $\mathrm{xvII}^{\mathrm{e}}$ dans la cité qui avait atteint avec les Revel, les Galien, les Philippe de la Salle, à une renommée sans égale. Mais, devant les faits établis par les documents que nous avons pu recueillir, on doit conclure que si Grégoire séjourna à Lyon, ce ne fut que bien peu de temps. Il n'était pas d'origine lyonnaise, et il ne faut pas oublier du reste qu'avant la Révolution les règlements sévères qui régissaient les corporations rendaient dans chaque ville très difficile à tous les étrangers, même avec la qualité de 
maître acquise dans une autre, l'exercice d'une industrie, qui en faisait de nouveaux concurrents.

Gaspard Grégoire était d'Aix en Provence, où il naquit le 20 octobre 1751, ainsi qu'en fait foi l'Acte de Baptême, extrait des registres de la paroisse Sainte-Magdeleine (1). Fils de Gaspard Grégoire et de Thérèse Bérage, il appartenait par tous deux à des familles qui occupaient les premiers rangs dans la corporation des marchands d'Aix, et justement figuraient parmi ceux fabriquant et négociant les tissus de soie, marchands « soiriers ", comme ils sont qualifiés dans les Actes officiels et délibérations de ces corporations de la cité provençale.

Depuis longtemps, en effet, non seulement dans toute la Provence on cultivait le mûrier pour l'élève du ver à soie et la récolte des cocons, mais on fabriquait, à Aix notamment, des étoffes de soie. Le fait est établi par l'extrait suivant de l'inventaire des archives de la ville d'Aix en Provence, antérieures à 1790 (en cours d'exécution), par $M^{\mathrm{r}}$ Maurice Raimbault (art. BB 26, fo 19) :

«Traité passé avec Antoine Carrat d'Avignon qui avait " créé à Aix l'industrie de la soie, du velours et des rubans, « en vue de laquelle 10,000 mùriers avaient été plantés en “ 5 ans à Aix et dans les environs : Carrat s'engage à main" tenir son usine à Aix pendant un nouveau laps de 5 ans " et la ville lui paie le loyer de la maison des Trois Rois, " où il avait son établissement, ainsi que celui des moulins « à teinture (2-9 juin 1545)).

D'où il ressort que la création de cette industrie à Aix remonte à 1540 . Depuis lors, les autorités tant de la ville que de la province ne cessèrent d'encourager la culture du mûrier et les manufactures de soieries. Toujours dans les archives d'Aix (BB 102, fo 70 ) nous voyons que :

" Dans une séance du Conseil en date du 18 juin 1645, " l'assesseur annonce qu'il y a à Aix des ouvriers qui ont " commencé à " tirer » du taffetas et exprime l'espoir que “ d'autres y fabriqueront bientôt du satin et autres étoffes

(1) Pièce justificative $\mathrm{n}^{0} 1$, 
" de soie. Le Conseil décide de faire faire une marque pour " estampiller toutes les étoffes de soie fabriquées dans la " ville. Cette marque sera déposée au greffe de l'Hôtel de "Ville."

Autre citation utile provenant des mêmes sources:

( Diverses personnes, ayant envie de venir créer à Aix des " manufactures de soieries, étaient sur le point d'y renoncer " par crainte des procès ruineux que leur faisaient les com“ munautés religieuses, sous prétexte que leurs usines étaient " insalubres. En conséquence, le Conseil demande au Roi " d'intervenir en faveur de ces industriels (21 juin 1727). » (Arch. d'Aix, H, fo 244.)

Enfin, pour ce qui intéresse plus particulièrement notre sujet, nous avons retrouvé dans les registres conservés aux archives d'Aix, sur lesquels étaient consignées les délibérations officielles du corps des marchands et relatives, soit à l'admission de nouveaux maîtres, soit à la répartition détaillée des cotes ou sortes de patentes, que devait payer annuellement chacune des maisons faisant partie de la corporation, etc., etc., la mention, depuis les années environnantes de 1700 , d'une maison "Bérage et $\mathrm{C}^{\text {ie }}$ ), diversement imposée selon les années, tantôt comme de la $2^{\mathrm{e}}$ classe à 135 livres, tantòt comme de la $3^{\mathrm{e}}$ et de la $4^{\mathrm{e}}$ à des taux moindres. Parfois le mandataire de la maison n'est pas Bérage, mais un Grégoire, allié de famille autant qu'associé d'intérêts. En 1761, après la mort, l'année précédente, de Louis Bérage, la raison sociale devint "Bérage Grégoire et $\mathrm{C}^{\mathrm{ie}} »$. C'est sous ce titre qu'elle sollicita du roi une subvention de 35 sous par livre de soie, comme avaient les établissements du Languedoc et du Dauphiné (Arch. des Bouchesdu-Rhône, C 779, fo 130). On la lui accorda et elle la toucha longtemps, sans doute jusqu'à la Révolution.

Si nous nous sommes un peu étendu sur ce qui précède, c'est pour montrer que Gaspard Grégoire, l'inventeur des velours peints, avait ainsi, de par sa ville natale et sa famille, les moyens d'acquérir les connaissances dans l'art de la fabrication des étoffes qui lui furent nécessaires pour réaliser son invention, sans avoir à aller les chercher ailleurs. 
Son père, prénommé Gaspard lui-même et fils d'un Gaspard Grégoire (1), en raison d'un usage provençal traditionnel, rendant souvent malaisées les recherches généalogiques, était né en 1714 (2) et mourut en 1795; il était devenu en 1750 (3), en épousant sa cousine Thérèse Bérage, le gendre de ce Louis Bérage dont il fut l'associé et le successeur, et plus tard, en 1777, s'associa avec ses fils pour continuer les mêmes affaires.

Très considéré dans le corps des marchands, dont il fut syndic en 1760 , il ne se laissait pas absorber par les besognes commerciales au point de négliger des occupations plus relevées.

L'auteur érudit du livre très intéressant, Les Rues d'Aix, par Roux-Alpheran, nous apprend (vol. II, pages 33 et suivantes) que :

"Doué de beaucoup d'esprit et d'un caractère aimable et " gai, il a laissé en manuscrit quelques pièces de vers pro"vençaux..."

Et qu'il fut surtout connu par l'ouvrage qu'il fit paraître en 1777 : Explication des jeux de la Fête-Dieu à Aix, relation de ces jeux institués, dit la tradition, par le roi René en 1462, jeux où le profane se mêlait beaucoup au sacré, qui restèrent longtemps en honneur dans la capitale de la Provence et dont furent tentées plusieurs reconstitutions, entre autres en 1851. Roux-Alpheran nous dit aussi que :

“ L'aimable poète provençal avait eu de nombreux enfants " (huit), dont trois méritent d'être mentionnés :

" Louis-Denis Grégoire, né en 1750, qui fut secrétaire de " la musique de l'empereur Napoléon, puis de la Chapelle « du roi Louis XVIII.

(1) Ce Grégoire, conseiller de ville en 1720. était chargé par l'Assemblée d'examiner un écrivain et arithméticien que la ville songeait à prendre à son service (délibération du 27 juin 1720 , Arch d'Aix BB 108, fo 38). Il était nommé Trésorier de la ville le 2 février 1724 (arch. d Aix, H, fo 134).

(2) Il habitait dans la maison qui est la dernière de la ligne septentrionale la plus voisine de la porte de la Plate-Forme et faisant le coin de la rue de la Fonderie : c'est là que naquirent tous ses enfants.

(3) Acte de mariage, archives de la ville d'Aix, GG 63, paroisse SainteMagdeleine. 
« Gaspard Grégoire, né en 1751, l'auteur de l'ingénieux " procédé au moyen duquel il exécutait en velours des por" traits d'une vérité frappante, des fleurs, des tableaux même " de la plus ravissante fraîcheur.

"Paul-Pierre Grégoire, né en 1755, muet de naissance et " peintre assez distingué. "

(Avant ce dernier, par ordre de naissance, mentionnons encore: une fille Catherine-Louise, née en 1753, qui fut sœur de la Miséricorde, et un autre fils Dominique-Alexandre, né en 1754, mort en 1802.)

" Les trois frères Louis, Gaspard et Paul avaient concouru " à la publication de l'ouvrage de leur père sur la Fête"Dieu. en dessinant les figures, notant les airs, et gravant " les planches qui accompagnent cet ouvrage. »

La constatation que Gaspard Grégoire appartenait à une famille de tendances et de goûts certes au-dessus de la moyenne, nous semble des plus intéressantes, et sa collaboration à l'illustration de l'ouvrage paternel montre qu'il avait à 26 ans, dans une mesure que la suite a prouvée, les dons et les aspirations d'une nature d'artiste. Dans cette année 1777, le 4 juin (1), il était admis avec deux de ses frères : Louis-Denis et Dominique-Alexandre, comme Maître, en qualité de fils de Maître, dans la corporation des Marchands d'Aix, réunie en assemblée générale :

" A l'effet de jouir de tous les droits, honneurs et préro" gatives y attachés".

Il prenait place dans la maison de son père, devenue Grégoire père et fils, et signait parfois, comme mandataire de la raison sociale, Grégoire cadet, sur les registres des délibérations du corps des Marchands, dont nous avons parlé. Nous avons relevé notamment sa signature en $\mathbf{1 7 8 2}$.

C'est à ce moment sans doute que, tout en s'occupant avec son père et ses frères de la marche de la manufacture et de leur commerce d'étoffes, il eut l'idée de ses velours peints et qu'il entreprit ses essais pour réaliser son invention, suggérée évidemment par le procédé connu du chinage,

(1) Pièce justif. no 2. 
mais toutefois présentant avec cette méthode des différences très notables et donnant des résultats bien supérieurs, au point de vue artistique tout au moins.

Nous verrons, par l'étude du procédé de Grégoire, qu'il fallut certainement toute une somme d'études, de recherches, de tâtonnements, de temps passé et aussi, par suite, de dépenses faites, pour qu'il eût en mains ses premières œuvres, celles qui excitèrent l'étonnement et l'admiration de ses proches, de ses concitoyens, et de tous ceux qui les virent à Aix.

Plein d'espoir et de confiance dans l'avenir de sa découverte, illusionné peut-être sur son développement futur au point de vue de l'application pratique et commerciale, il devait naturellement chercher à en tirer gloire et profits. Pour ce faire, Aix n'était pas, somme toute, un centre assez important ni assez visité ; d'autre part, le commerce y laissait probablement de moins en moins de bénéfices, à la veille de temps qui allaient devenir de plus en plus troublés. Tout concourait donc pour que Grégoire tournât ses regards vers Paris; c'était là seulement qu'il pourrait présenter son invention à des amateurs nombreux, riches et influents, faire consacrer son succès et obtenir un privilège, faveur qui s'y dispensait tant par suite du mérite des inventions en elles-mêmes, que de la valeur et de la solidité des recommandations dont elles étaient appuyées. Or, la famille Grégoire était en relations avec une autre famille aixoise, celle des David, dont un des membres, Antoine David, était imprimeur de la ville et du Parlement. Il avait un neveu qui devait obtenir plus tard une certaine notoriété dans le monde des arts, de la littérature et de l'archéologie, sous le nom d'Emeric David (Biographie générale de Hoefer. Art. Emeric David). Destiné d'abord à la profession d'avocat, il s'était fait recevoir docteur en droit dans sa ville natale en 1775 , puis se rendit à Paris pour y compléter ses études de jurisprudence. Il devait, vers 1787 , retourner à Aix, succéder à son oncle, devenir à la Révolution, dont il adopta les principes avec franchise, maire en 1791 , puis en 1793 , quand les passions étaient déchaînées et que régnait la loi des 
suspects, être obligé d'échapper par la fuite à des mandats d'arrêt. Après le 9 thermidor, il revint à Paris et reprit, avec la profession d'avocat, ses études littéraires et artistiques, le tout entremêlé encore de spéculations financières.

D'après des correspondances et documents extraits d'une série très importante des lettres et papiers divers de cet Emeric David, fort prolixe, venue par succession à la $\mathrm{Bi}$ bliothèque de l'Arsenal, nous voyons qu'il fut à différentes reprises en relations suivies avec les frères Grégoire.

Ce sont d'abord des lettres (Bibl. de l'Arsenal 5979) de sa mère relatives au départ pour Paris d'un Paul Grégoire, sans doute le troisième fils de Gaspard, qu'Emeric avait accepté de loger chez lui et de guider pour ses débuts dans la vie de la capitale; - lettres de son oncle, également. Dans les unes et les autres, on donne à Emeric de sages conseils et on fait des recommandations entremêlées de critiques, à propos de cette charge qu'il a assumée, etc. Et tout nous porte à croire que, lorsque Gaspard Grégoire se décida à venir à Paris, ce fut son ami Emeric qui lui facilita de même son installation et le guida pour ses démarches. Quand le fait se produisit-il? Nous n'avons pu l'établir exactement. Quoi qu'il en soit, de lettres trouvées aux Archives nationales, il résulte que dès 1785 notre inventeur était à Paris et devait y être depuis quelque temps déjà ; le 15 octobre 1785 , il écrivait au Département des Arts de la Maison du Roi (probablement à un secrétaire) :

" Je suis occupé à remplir mes engagements et j'emploie " tout mon zèle à ce que mon travail soit à la satisfaction de «M. le Comte d'Angiviller. Je vous prie de vouloir " bien lui demander un ordre pour recevoir la somme de " deux mille livres à compte des deux tableaux que je me " suis engagé à faire.

" J'ai l'honneur d'être avec la plus parfaite considération, Monsieur,

"Votre très humble et très obéissant serviteur.

(Arch. Nat. $0^{1} 1919$, p. 5.)

"G. GréGoIre." 
Le haut fonctionnaire, qui dirigeait à cette époque le Département des arts, était en effet le comte d'Angiviller (Charles-Claude de Flahaut de la Billardrie), Conseiller du Roi en ses conseils. Directeur et Ordonnateur général des bâtiments de Sa Majesté,jardins, arts, académies et manufactures royales. C'était à lụi que Grégoire avait pu arriver à présenter les premiers essais de ses velours, essais imparfaits sans doute, le procédé si délicat qui permettait de les obtenir n'étant pas encore au point. C'était de lui qu'il avait obtenu des encouragements et aussi, chose plus importante, une aide matérielle. Il ressort, en effet, d'autres correspondances qu'il reçut des subventions en argent assez fortes et fut logé aux Galeries du Louvre. Ce point est établi, entre autres, par une lettre adressée, dès le 5 septembre 1785 , à M. d'Angiviller, par un sieur Renard de l'Administration des Beaux-Arts (Arch. nationales, $\mathrm{O}^{1} 1674$, Maison du Roi), et qui débute ainsi (1) :

"La nécessité qui oblige M. Grégoire à vous demander " la suppression du dernier plancher au Logement que vous " lui avez accordé aux Galleries du Louvre, me paraît fondée " relativement à l'établissement de métiers qu'il doit " faire dans ledit logement, et en conséquence de la hau" teur dont il a besoin ; celle de l'étage qu'il a préféré ne " suffit pas pour les placer. "

C'était beaucoup que d'avoir obtenu cette faveur d'un logement au Louvre, si recherchée par les artistes et les artisans les plus habiles depuis que Henri IV avait voulu faire del'édifice somptueux une sorte de monument d'utilité publique, avec la pensée d'honorer le talent, de le récompenser et de provoquer l'émulation; elle excitait de nombreuses compétitions avec encore la jalousie des corporations (Hist. gén. du Vieux Paris, par Berty).

Seulementle comte d'Angiviller, sans doute amateur éclairé autant que grand seigneur de cette fin de siècle fastueuse, avait bien été séduit par la nouveauté et le charme des premières œuvres de l'artiste aixois; il avait bien pensé aussi

(1) Pièce justif. $n^{0} 3$. 


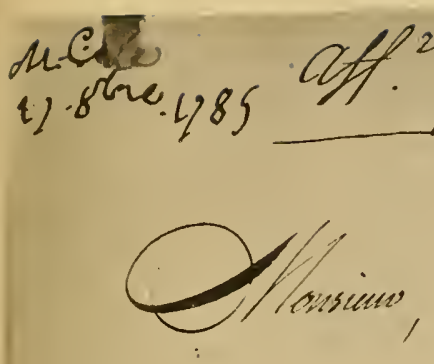

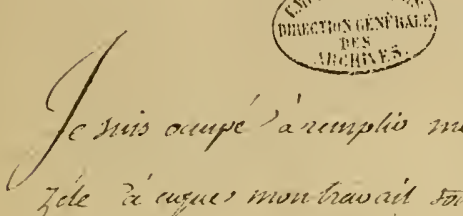

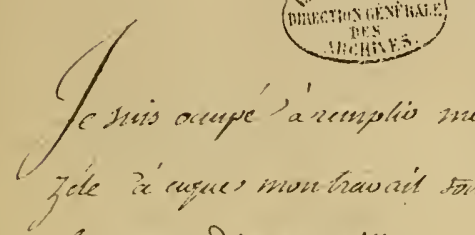

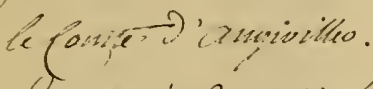

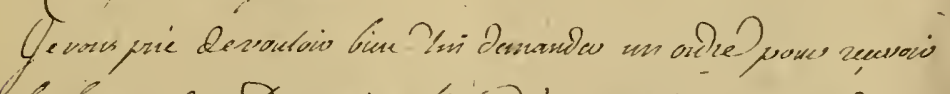

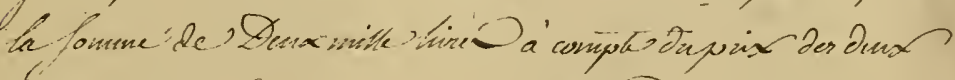

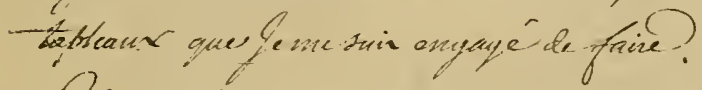
Esraisan o. Greproire row Capate dentathleamo eu velouro canpe' an a pail:

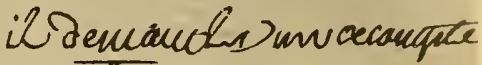
de 2.00 le $19.8^{\ln 2}-1785$. A. Lep. G. en a jo amicis incivitions?

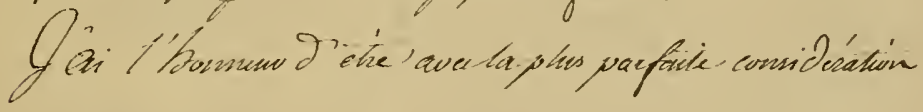
Consium

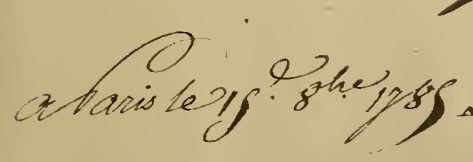

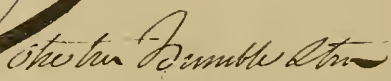
Brisant fervitum

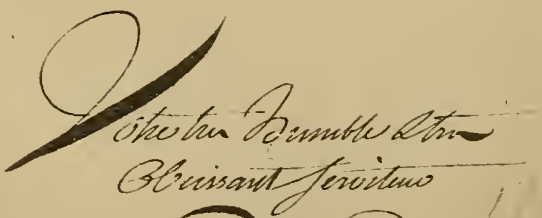

Xatepre?

Phototypie Berthaud

FaC-simile d'Une lettre a M. D'Angiviller. 

qu'il y avait là une tentative ingénieuse et susceptible d'une utilisation plus étendue et digne d'être encouragée, mais il avait exigé davantage de l'inventeur.

Nous expliquerons à l'éiude technique du procédé pourquoi une des conditions à peu près inéluctables de la réussite du velours peint, est qu'il soit exécuté en petites dimensions. Or, quand M. d'Angiviller avait donné son appui officiel à Grégoire, c'était à la condition qu'il se chargeàt de faire des tableaux de grandeur importante. Celui-ci, fort de ses premières expériences et de son habileté, ne crut pas devoir éluder cet engagement en présenced'arantages immédiats. Les choses n'allèrent pas cependant tout comme il l'espérait, et les résultats furent médiocres; ils ne donnèrent pas satisfaction à M. d'Angiviller, d'où reproches et commencement de défaveur. Nous voyons que, par un mémoire en date de 22 août 1786 (1), le sieur Grégoire essaye d'effacer la mauvaise impression produite par son échec et sollicite une nouvelle aide financière pour lui permettre de continuer ses essais en grand. Rendu plus prudent, il rappelle ses difficultés premières, les entremêle de réserves habiles, le tout dans le style composé d'un solliciteur d'alor's, qui s'adresse au grand personnage dont dépend sa fortune :

" Le sieur Grégoire, - dit-il, - a eu l'honneur de présen" ter ses premiers essais en velours à M. le Comte d'Angi"viller, qui a daigné les accueillir avec bonté ; il aurait dû " sans doute s'assurer auparavant de pouvoir exécuter des " objets en grand comme les seuls qui puissent intéresser "M. le Comte; mais le sieur Grégoire, " n'étanı pas "fabriquant" (sic), il n'a eu la permission de travailler « nulle part ; c'est cette permission qu'il est venu solliciter à " Paris ; ce n'est même qu'après beaucoup de peines et " d'épreuves qu'il a pu réussir à Lyon à exécuter ses petits " essais. "

Cette phrase est des plus intéressantes à relever : Grégoire, insistant sur les difficultés qu'il a eu à surmonter, expose ce que nous avancions plus haut, les raisons mêmes qui nous

(1) Pièce justif. no 4 . GRÉGOIRE 
font dire que son passage à Lyon ne fut que de bien courte durée. Faut-il, d'autre part, entendre ces mots «n'étant pas fabriquant " comme en contradiction avec cette profession de marchand soirier ou drapier à soie que nous avons établie pour ce qui le concerne, quand il était à Aix associé avec son père et ses frères? nous ne le pensons pas. Il lui fallait, pour le tissage des velours qu'il avait entrepris de décorer par la peinture, des ouvriers très habiles, très experts en la fabrication d'une étoffe particulièrement difficile à faire; il est naturel qu'il soit venu les chercher à Lyon, où il se heurta en effet du reste aux complications à prévoir du fait des règlements corporatifs. Et la lettre citée plus haut, relative à l'aménagement de ses métiers à velours dans le logement qu'il occupait, dit bien aussi :

" M. Grégoire vous prie de l'honorer d'une prompte ré" ponse afin que les ouvriers qu'il a fait venir de Lion " puissent travailler très incessamment aux objets que vous " lui avez confiez (sic)."

" Le sieur Grégoire, - continue le mémoire, - s'est en" gagé à l'exécution du portrait de la Reine et d'un tableau " de fleurs, sans promettre un entier succès; le porirait de " la Reine a mal réussi, cela est vrai, et le tableau de fleurs " en conséquence n’a pas été exécuté. \#- Voilà l'aveu de sa déconvenue, mais il s'excuse de suite et dit encore: " C'est la première fois que le sieur Grégoire a entrepris un " ouvrage dans la largeur du velours (1); le logement qu'il " occupe n'étant pas disposé favorablement pour ses métiers, " les opérations ont été pénibles et défectueuses, mais 》nouvelles promesses : - " il est assuré du moins de pou" voir à l'avenir exécuter assez bien des ouvrages de cette " grandeur, ce qui était incertain auparavant."

Et le reste du mémoire est consacré à des phrases assez alambiquées de défense de son invention, de promesses modérées et de remerciements anticipés, et il faut croire que la somme dont il s'agissait - 3.000 livres — fut bien touchée

(1) La largeur du velours au fer à la main était et est encore d'environ 48 à 50 centimètres. 
et que les essais continuèrent pour arriver à ces velours « en grand », qui seuls intéressaient M. d'Angiviller. Grégoire terminait son plaidoyer: "En espérant que les bontés de M. le Comte ne seraient point infructueuses ", et cependant elles le furent à n'en pas douter, au moins pour le but à atteindre, fixé par le grand-maître du Département des Arts de Louis XVI.

Nous voyons, en effet, par une lettre qui lui est adressée d'Aix, le 31 juillet 1787 (1), par le père de Grégoire, qu'il est arrivé des changements considérables et désastreux dans la façon dont est traité son fils. Son crédit a baissé au point que le logement, dont il avait été gratifié au Louvre, lui est retiré pour être donné au peintre Lagrenée, et il semble bien que la source des munificences royales dispensées par les Beaux-Arts est tarie. La lettre du père intervenant pour son fils est digne et calculée; elle mentionne une série de points intéressants et débute en ces termes :

«Monsieur le Comte, l'accueil favorable que vous avez " fait à mon fils, lorsqu'il a eu l'honneur de vous présenter " son nouveau genre de tableau en velours, la bonté que " vous arez eue de lui accorder un logement aux"galeries du ( Louvre, et de lui faire donner un encouragement en argent, " l'éblouirent si fort qu'il se décida de quitter le commerce " pour se livrer entièrement à ce travail et à des découvertes " ultérieures, d'accord avec moi et toute ma famille, qui " heureusement ne faitqu'un tout. Persuadé que ces ouvrages " seraient présentés à Sa Majesté, ainsi que vous l'avez tou" jours fait espérer à mon fils, j'en ai attendu la réussite pour " n'avoir qu'un remerciement à vous faire. Deux ans se sont " écoulés sans que j'aie eu cette flatteuse satisfaction. J'ai la " douleur d'apprendre aujourd'hui, après ce long espace de " temps et après les dépenses particulières que j’ai faites, " qui sont ruineuses (pour un père qui a huit enfants), que " toutes ces espérances sont évanouies au point que le loge" ment de mon fils doit être occupé sous peu par M. Lagre" née ». Là-dessus le ton se fait apitoyant : "Cela étant,

(1) Pièce justif. $n^{0} 5$. 
«Monsieur le Comte, que doit devenir ce cher fils, auquel “ je n'ai rien à reprocher ? Les dépenses excessives étant de " première nécessité pour sa nourriture et celle de son frère “(Paul Grégoire, le peintre dont nous avons parlé), celles " des ouvriers qu'il a encore en grande partie, celles pour le " prix des soies achetées à Lyon et en Piémont, des métiers, “ des petits meubles et généralement pour l'entretien le plus " simple, etc., etc. ». Et le père, toujours avocat de son fils, de défendre la valeur de ses ouvres: "Je ne peux pas douter, "Monsieur le Comte, de la beauté des ouvrages de mon fils, " par l'estime que vous en avez faite vous-même, par celle de «M. Boutin, du Conseil Royal des Finances, de M. le Comte " de Thiers, du fils de M. de Miromesnil, de presque tous " les membres du Parlement de la Cour des comptes de "Provence et généralement par l'approbation de tous les " amateurs d'Aix, de Marseille, de la Province, et d'un nombre " infini de seigneurs anglais qui me sont tous adressés par " tant de maisons de banque, etc., etc. On n'en a même vu « que les premiers essais qui ont été admirés par toutes ces " personnes si recommandables qui sont venues les voir chez " moi. »

Ces arguments un peu en dehors de la cause et les paroles de flatterie qui terminent la lettre ne touchèrent pas M. d'Angiviller, tout à son idée de velours en grand que Grégoire n'arrivait pas à obtenir convenablement, ou peutêtre parce qu'il était circonvenu par d'autres influences; tant d'intrigues devaient s'agiter alors, comme de tout temps, autour des faveurs gouvernementales. Le "Protecteur-né des Arts n, comme l'appelle en dernier ressort Grégoire père à la fin de son plaidoyer, lui fit répondre, comme il est résumé sur la pièce même, à la façon administrative, mais catégorique :

" Répondre en déduisant avec honnêteté et même complai" sance, les considérations qui combattent les vues de son " fils, sur ce qui est grâces à obtenir du Gouvernement qui " ne peut et ne doit en accorder qu’à des découvertes utiles " et vérifiées."

Cette défaveur marquée était certainement pour l'artiste 
inventeur un coup très rude; il essaya encore de l'atténuer et de regagner la confiance perdue. Le 13 septembre 1787 (1). il écrit lui-même à M. d'Angiviller une longue défense :

" Mon père m'a fait part de la lettre que vous avez bien " voulu lui écrire en réponse à celle qu'il a eu l'honneur de "vous adresser. Je vois que vous êtes toujours dans les " mêmes idées relativement à mes petits ouvrages que vous " ne croyez pas susceptibles de donner lieu à une spécula" tion avantageuse. Il est vrai que je ne sais pas jusqu’à quel " point je réussirai à en adoucir le prix (2), mais quoi qu'il " en puisse être, je suis assuré qu'il sera toujours très modéré " et je désire très fort d'en courir le risque. " Affirmation un peu avancée, mais il faut joner le tout pour le tout, et il ajoute :

"Quant aux objets en grand qui sont les seuls qui vous " intéressent, vous êtes trop persuadé que l'on ne doit pas y " compter ; cependant j'ai lieu de croire que je pourrai exé" cuter des sujets de fleurs pour meubles et copier des " tableaux dans la largeur du velours ; je suis assez assuré " pour pouvoir le promettre. Les essais que vous m'avez " ordonné de faire vous ont fait oublier cet espoir, quoiqu’il (" soit augmenté pour moi. "Voilà bien qui témóoigne de la foi robuste de l'inventeur, car il n'y a pas eu, que nous sachions, de ses velours réussis en véritablement grandes dimensions. Revenant sur la décision à laquelle il ne peut se faire après les espoirs entrevus :

( J'ai, dit-il, un ordre de votre part ce 30 juillet, pour " quitter les Galeries du Louvre, avant qu'il y eut aucune " décision (pour ce privilège qu'il sollicite encore plus loin), " de sorte que depuis ce temps, je suis sans état avec des " ouvriers à nourrir. " Et il continue le chapitre des doléances :

"Quand je me suis engagé d'entreprendre des ouvrages " difficiles, j’ai dû calculer mon tems $(s i c)$ et mes dépenses,

(1) Pièce justif. $n^{0} 6$.

(2) Cette considération de prix avait bien son importance, et forcément, comme nous le verrons, le coût des velours de Grégoire devait être élevé. 
“ mais je n'ai pas dû croire que j’aurais à attendre encore à ce “ moment une décision sur mon établissement; ma fortune « ne peut résister à de pareilles épreuves, mais j’espère de " votre justice que vous voudrez bien m'accorder un dédom« magement pour le temps et les dépenses que j’ai employées " depuis plus de seize mois que j'ai eu l'honneur de vous ( remettre mes ouvrages. Il est bien malheureux pour moi « d'aroir dépensé vingt mille livres depuis que j'ai quitté ma «famille et mon commerce, sans avoir obtenu la permission « de travailler et d'être encore dans l'incertitude de savoir si « je pourrai faire état de ma découverte et si l'on m'en accor" dera la propriété par un privilège. " Enfin, avec le ressort d'un esprit chercheur, il veut intéresser M. d'Angiviller à de nouvelles idées :

« Vous n'avez pas oublié sans doute, Monsieur le Comte, " que j'ai eu l'honneur de vous dire, il y a plus de deux ans, " que j'avais trouvé une méthode pour noter les couleurs, et " que, depuis ce temps, ayant trouvé le moyen de pouvoir “ exécuter sur un métier monté en velours la couleur qui me « sera demandée, je vous ai proposé d'en faire l'expérience. « Je n'attens plus que le moment de pouvoir donner une “ application utile à ces découvertes. » Et il termine sur un nouvel appel à la bonté de $\mathrm{M}$. le Comte pour lui permettre de sortir des embarras matériels où il se trouve.

La pièce ne porte pas de mention qui puisse donner lieu de croire qu'il fut répondu et favorablement à ce cri de détresse. Ainsi donc notre inventeur, après aroir fondé sur sa décourerte les plus solides espérances étayées sur des encouragements qui l'avaient " ébloui », allait connaître les déceptions et les déboires. Cela pouvait être aussi pour lui, privé de tout appui officiel, la gêne matérielle, exagérée peut-être un peu à dessein daus ses lettres; mais il ne se tint pas pour battu et dut user de toutes les influences dont il pouvait disposer pour les faire jouer en sa faveur, car une lettre du 14 octobre 1787, signée Lambert, du Département des Arts (Arch. 11., $0^{1} 1919$, p. 5), nous fait voir que c'est à l'Administration du Commerce que Grégoire a été renvoyé et à laquelle il adresse ses sollicitations. C'était $\mathrm{M}^{\mathrm{r}}$ Tolozan ou 
plutôt de Tolozan (à partir de 1784 à l'Almanach royal), originaire de Lyon, où son père était marchand et secrétaire du Roi en la Chancellerie près la Cour des Monnaies de cette ville, qui présidait le Bureau du Commerce, réunion des quatre anciennes Intendances, avec les attributions d'un véritable ministre, depuis le règlement du 5 juin 1787. Grégoire avait dù être instamment et utilement recommandé à ce haut fonctionnaire, qui demande, en juillet 1787, nous dit le sieur Lambert dans la lettre ci-dessus citée, que l'artiste lui remette un échantillon de ses ouvrages: "Afin qu'on " puisse juger du degré d'encouragement dont sa découverte " est susceptible et de quelle utilité elle peut être pour le "Commerce du Roïaume. "

Et puis, comme le postulant ne se lasse pas et multiplie pétitions et démarches, nous retrouvons toute une série de délibérations du Bureau du Commerce, avec rapports, avis consultatifs et discussions même, sur les mérites et la valeur de son invention. (Arch. nat., Registre du Bureau du Commerce, $\mathrm{F}^{12}, 107,108$, etc.)

Dans la séance du 28 février 1788. M. de Tolozan expose que le sieur Grégoire a demandé: "Une autorisation et des " encouragements pour exercer l'art de faire en velours de " petits tableaux, représentant des fleurs, des paysages, des " animaux et des figures", soit, " en dédommagement de " ses dépenses considérables, un privilège exclusif de « 15 années pour la fabrication de ses tableaux et une somme " de trente mille livres, - avec en plus l'exemption de “ droits, tant à la sortie qu'à la circulation des tableaux en " velours qu'il fabriquera. "

M. Desmarets, de l'Acådémie royale des sciences, et le Sieur de Lausel, inspecteur ambulant des manufactures, chargés d'examiner la nature du travail et des procédés employés par le Sieur Grégoire, ont déposé un rapport favorable, disant en résumé : "Que par la correction des con" tours et l'insensible dégradation des nuances, le travail du "Sieur Grégoire était, sans aucune proportion, supérieur "à tout ce que les fabricants de Lyon avaient fabriqué jus" qu’à présent pour exécuter des fleurs et des figures en 
« velours à trois et quatre couleurs; que cette perfection « n'était point l'effet de couleurs appliquées sur un-velours " tout fabriqué, mais qu'il est manifeste que ce sont uni" quement les soies formant le velouté qui d'abord ont été " teintes et fabriquées ensuite, pratique usitée pour le Chiné, " et que si sous ce point de vue l'art du Sieur Grégoire n'est " point une découverte, il estau moins un perfectionnement " porté à un degré dont personne n'avait l'idée. »

Un autre expert, par exemple, le Sieur Brisson, lui aussi inspecteur ambulant des manufactures, consulté, dit tout au contraire que les tableaux du Sieur Grégoire ont été exécutés sur un velours tout fabriqué.

Là-dessus on délibère, mais on sent qu'il y a des influences contre Grégoire, et plusieurs de MM. les Commissaires élèvent des objections, se montrent nettement opposés à la demande de privilège, et surtout à celle de "secours considérables " en argent pour une invention dont ils contestent l'intérêt. "Il est indispensable, disent-ils, de com« mencer par constater le degré de perfection auquel les " velours fabriqués en 3-4 couleurs avec des soies teintes « en réserve a été porté à Lyon, et enfin jusqu'à quel point "l'art du Sieur Grégoire peut être utile au Commerce " national. "

L'assemblée décide de soumettre les divers rapports aux députés du commerce. Ceux-ci font connaître leur avis le 27 mai 1788, avis qui est rappelé à la séance du 26 juin du Bureau présidé par M. de Tolozan. Les députés du commerce disent qu'ils ne se prononceront pas affirmativement sur les procédés qu'emploie le Sieur Grégoire ; ils émetient eux aussi de nombreuses objections qui paraissent plus inspirées par un esprit de chicane mesquine el de concurrence dépitée au fond, que soutenues par la solidité des arguments. En fin de compte, ils pensent que cet objet " tient absolument aux " Arts comme la gravure et la peinture et ne peut faire un " article de commerce, ni ètre d'aucun secours à nos ma" nufactures; qu'on peut accorder ce privilège pour neuf " ans seulement, et qu’à l'égard des trente mille livres que " demande le Sieur Grégoire, ils ne sont point d'avis de les 


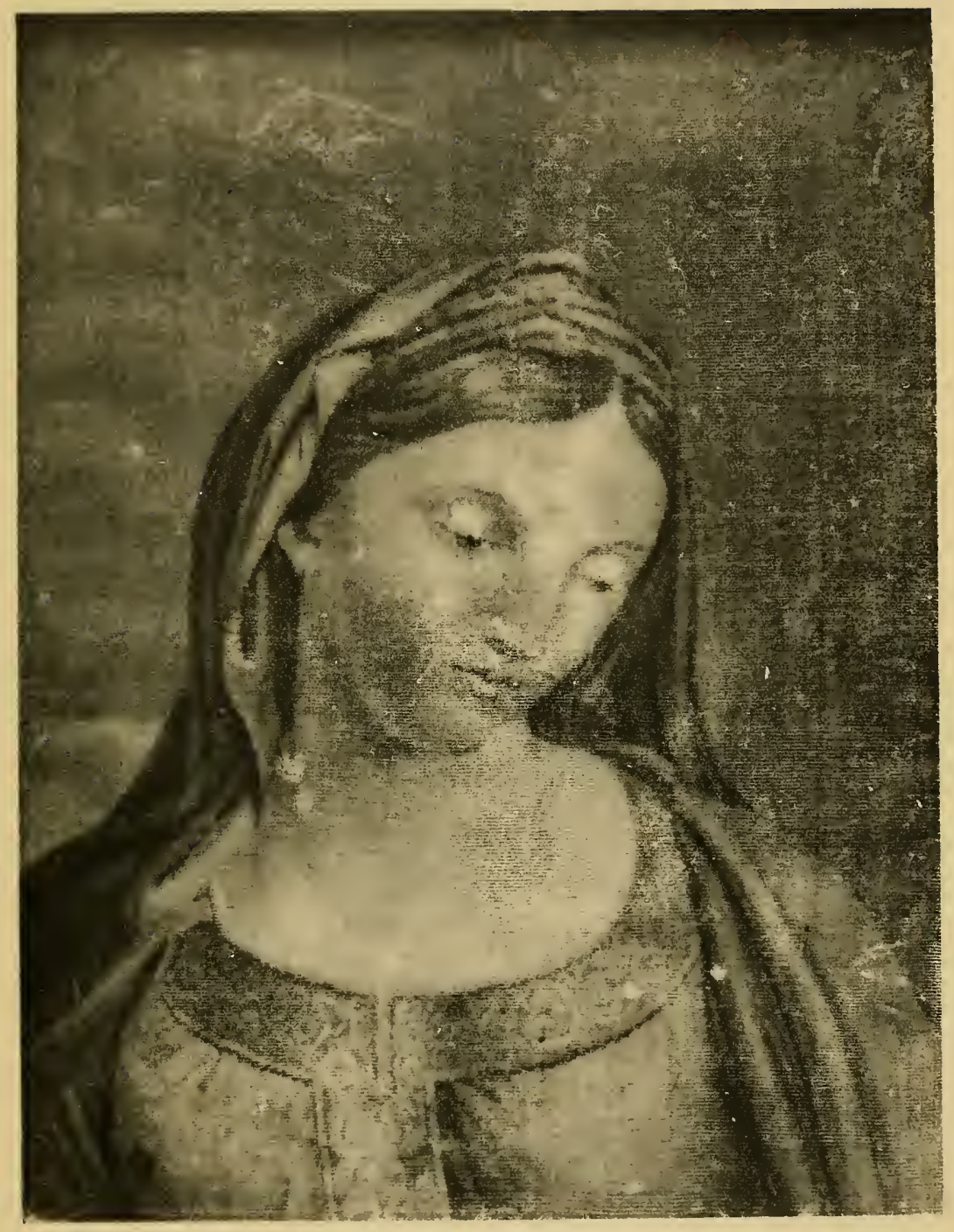

Madone 

" lui accorder. " Mais alors Grégoire eut encore l'appui et la défense de M. Desmarets, Inspecteur général du commerce, qui avait déjà rapporté favorablement son procédé ; il soutient dans cette même séance que ce procédé :

“ $1^{\circ}$ N'est pas le chiné, puisqu'on nue (c'est-à-dire qu'on " colorie avec une grande variété de nuances et de tons).

" $2^{\circ}$ Ce n'est pas la tire (c'est-à-dire le procédé de tissage " des étoffes à dessins brochés, brocarts, etc., employé avant "la mécanique Jacquard), puisque l'envers présente des " couleurs pareilles.

« 3० Ce n’est pas un simple dessin, puisqu'il ne faut que le " temps de fabriquer le velours pour passer d'une grandeur " à une autre.

" $4^{\circ}$ Ce n'est pas impression, car pour imprimer il faut " des couleurs empâtées qui arrêteraient l'exécution des " tissus."

"Ce n'est donc pas ce qu'on connaît déjà, mais une in" vention heureuse, à en juger par les résultats. " Et l'Assemblée, gagnée à la cause, décide d'accorder le privilège de 15 ans et 12.000 livres, sous condition, pour Grégoire, de faire la preuve qu'il n'emploie pas la tire ni le chiné, à l'effet de quoi il sera tenu d'exécuter en présence des sieurs Desmarets et Abeille, inspecteurs généraux du commerce et des manufactures, la fabrication de ses ouvrages et de donner par écrit son procédé, pour : " ledit procédé être rendu public à l'expiration des quinze années. »

Le 10 juillet suivant, M. de Tolozan annonce qu'il a rédigé le projet d'arrêt conformément à la délibération, projet qui est approuvé, en supprimant la qualification de petits objets pour les ouvrages dont le privilège sera accordé, et ce pour que le titulaire ait la faculté d'étendre son procédé autant qu'il lui sera possible.

Grégoire avait dû insister pour cette modification de rédaction, qui pouvait lui éviter des tracasseries ultérieures. Enfin, le 12 juillet 1788 (1), était rendu en sa faveur l'arrêt définitif en les formes consacrées, lui accordant le privilège

(1) Pièce justif. $n^{0} 7$. 
et les douze mille livres; et le 31 juillet, M. de Tolozan disait, au Bureau du Commerce, que MM. Desmarets et Abeille, commis pour être présents à la fabrication des ouvrages de velours imitant la peinture, avaient remis le rapport qu'ils avaient dressé à cet effet, daté de la veille et auquel ils avaient joint un paquet cacheté de leurs cachets et de celui du Sieur Grégoire contenant un Mémoire où les procédés de la confection desdits ouvrages étaient décrits d'une manière très suffisante. Le même rapport prévenait que ce paquet serait ouvert en présence du Sieur Grégoire, lorsque ses ateliers seraient montés, pour rédiger l'exposition et la description circonstanciées de ses moyens et procédés.

Ainsi, après beaucoup de temps, d'efforts et de démarches, notre artiste était enfin en possession de ce privilège qui allait lui permettre d'exploiter exclusivement son invention et de chercher à en tirer profit. Mais c'était un bien mauvais moment pour cela. A la veille de la Révolution, l'attention devait se porter fatalement plus vers la politique et les événements, que vers des nouveautés artistiques; il est vrai que Grégoire avait bénéficié d'une importante allocation qui pouvait lui faciliter sensiblement la continuation de ses essais et de ses expériences, en supposant qu'il en ait touché très intégralement tous les termes. Signalons qu'entre temps, il avait tourné dı reste sa réflexion vers d'autres sujets d'étude auxquels il revint fréquemment, comme nous le verrons. Dans le Journal de Paris du 3 juillet 1789, on parle du Mémoire sur la couleur des Bulles de savon, ouvrage qui a concouru pour le prix proposé par l'Académie des Sciences, Belles-Lettres et Arts de Rouen, en 1786, suivi de quelques observations particulières sur l'évaporation de l'eau et sur les propriétés des couleurs, par M. Grégoire, à Londres, et se trouve à Paris chez Bleuet fils aîné, successeur de Joubert l'ainné, libraire du Roi pour l'Artillerie et le Génie, Rue Dauphine, $\mathrm{n}^{\circ} 112$, l'an 1789,1 volume in- 8 de 75 pages, avec cette épigraphe : "Les couleurs embellissent les formes, " comme l'esprit embellit la raison. " Bibliothèque Montagne de Firmont.)

Dans ce curieux opuscule, l'auteur exposait, avec plus 
d'ingénieuse supposition que de rigueur scientifique, une explication de la coloration des bulles de savon, "par une " matière dont chaque particule, qui présente constamment " l'une des trois couleurs primitives, jaune, rouge et bleu, " est d'une pesanteur différente pour chacune de ces cou" leurs, etc. »

Cette question des couleurs devait passionner Grégoire toute sa vie; son invention même lui en avait fait éludier les mélanges et les lois; mais il en raisonna toujours en praticien empirique et averti cependant, plus qu'arec l'exactitude d'un homme de science; nous verrons plus tard qu'il devait classer ses idées dans plusieurs publications et notanment dans sa Table des couleurs.

Il continuait cependant à fabriquer ses velours peints, surtout ces petits sujets qu'il réussissait très bien, pour les offrir à une clientèle qu'il recherchait par la voie de la publicité, puisque l'on trouve dans les journaux du temps, notamment dans le Journal de Paris du 3 janvier 1790 et la Gazette de France du 5 janvier 1790 , des sortes d'annonces ou réclames, rédigées dans le style de l'époque et destinées à attirer l'attention du public et des acheteurs :

" Nous nous empressons d'annoncer une découverte très ( intéressante dı sieur Grégoire; elle consiste à exécuter, " sur les métiers, des tableaux en velours de soie dont le fini " égale celui des peintures les plus soignées. La perfection " de ce nouveau genre est faite pour surprendre également " les amateurs de mécanique et de peinture. On observera " aisément que les sujets de ces tableaux sont exécutés en " même tems que l'étoffe; les couleurs en sont très solides, " elles craindraient seulement d'être mouillées, mais elles " supportent le frottement même très fort d'un linge sur " l'étoffe sans être enlevées. Le Sieur Grégoire a été admis à * faire hommage à Leurs Majestés des prémiers ouvrages " qu'il a perfectionnés depuis l'époque où il a reçu du Roi et " du Gouvernement des faveur's qui l'ont encouragé. Ces " nouveaux objets seront vendus au Palais-Royal, au Prix " Fixe $\mathrm{n}^{\circ} 9$, où on les verra. Ils sont montés en boîtes, bon" bonnnières et médaillons ». (Gazette de France.) 
Il est difficile de savoir si la vente de ses velours, même ainsi adaptés ingénieusement à des bibelots, donnait à leur auteur des bénéfices très rémunérateurs; il vivait toujours avec son frère Paul, le peintre sourd et muet, et l'avait sans doute à sa charge. Cette même année 1790 , le 20 avril, il adresse encore une lettre à $M^{r}$ le comte d'Angiviller pour lui demander, très simplement, la faveur, pour ce frère, de prendre une copie du portrait du Roi, copie destinée à la salle de l'Hôtel de Ville d'Aix. La pièce porte cette annotation :

“ L'original ne peut être déplacé, il n'y en a qu'une copie au " sallon du dépôt à Paris. Mr le Comte, par égard pour la " situation si triste de cet artiste, est disposé en faveur de " sa demande, s'il y a moyen sans inconvénients (1). »

Ces mots " si triste » s'appliquent vraisemblablement à la malheurense infirmité de Paul Grégoire, mais on est presque tenté d'y voir une allusion aux embarras dans lesquels pouvait se trouver Gaspard lui-même, et, rapprochement curieux, sans que nous voulions du reste en tirer de conclusion, il était alors domicilié à l'ancien Hôtel de la 'Trésorerie, 22, Enclos du Temple. Or, le Temple, propriété de l'ordre de Malte et séjour du Grand-Prieur, était une enceinte où s'exerça jusqu'à la Révolution ce droit d'asile issu de coutumes féodales: on ne pouvait y être recherché pour des délits, non plus que tracassé par ses créanciers. (Arch. de la Seine, collection Lazard.)

A ce moment déjà les jours troublés étaient commencés, et ce n'était pas certes pour aider un homme luttant contre bien des difficultés.

Fori heureusement nous ne voyons pas qu'il fît autrement que se tenir à l'écart de la politique; sa peusée n'était pas là, et, s'il eut un homonyme bien connu dans les rangs de la Convention, c'était cet abbé Grégoire, auquel ne le rattachait aucun lien de parenté ni de concitoyenneté (2). Il continua

(1) Ce portrait fut exécuté et placé en grande pompe à Aix, le 16 juillet 1790 ; il est peut-être encore au musée de cette ville.

(2) L'abbé Grègoire est né à Vẻho, près de Luuéville 
donc à s'occuper de ses velours et à les faire annoncer dans la presse. En 1793, le $n^{\circ} 1587$ de l'Almanach sous verre publie, colonne 674, une notice sur les Tableaux en Velours.

L'auteur n'est pas nommé, mais la rédaction en est toute pareille à ceux des précédents avertissements que nous avons cités.

Cependant il fallait vivre; les besognes artistiques ou ingénieuses ne nourrissaient pas, paraît-il, comme souvent, leur homme, et nous en arrivons à cette constatation un peu surprenante au premier abord, mais fort peu douteuse, d'après plusieurs correspondances et notamment celles trouvées dans les papiers d'Emeric David à l'Arsenal dont nous avons parlé plus haut, que Gaspard Grégoire s'est occupé, particulièrement avec l'un de ses frères Dominique, de banque et d'affaires semblables pendant le Directoire et le Consulat. Emeric, revenu à Paris, comme on sait, après le 9 Thermidor, était doué d'une activité qui s'attaqua à toute espèce de sujets avant de se tourner définitivementvers l'étude des arts et des lettres. Il parait bien que, domicilié rue Neuve-desPetits-Champs, près celle d'Antin, $\mathrm{n}^{\circ} 47$, selon une expression moderne, il brassa divers genres d'affairés. Il avait été avocat, puis imprimeur, il fut courtier d'assurances, trafiquant, banquier, et, comme tel, en relations avec les frères Grégoire, ses amis d'autre part. De la raison sociale Grégoire et $\mathrm{C}^{\mathrm{i}^{\mathrm{e}}}$ ou Grégoire frères, Gaspard fit partie, mais certes moins agissante que Dominique, qui lui aussi avait quitté Aix pour la capitale, à la suite des événements révolutionnaires, causes de profonds changements dans les conditions d'existence des marchands. Le père de famille était mort en $\mathbf{1 7 9 5}$, le frère aîné Louis, à qui ses talents de musicien devaient faire obtenir plus tard une fonction impériale, avait quitté Aix ; la maison de commerce n'existait plus et la famille était dispersée. Aussi, à tout bien prendre, n'y a-t-il rien de très étonnant à voir des gens comme ces Grégoire, ayant eu les uns et les autres leur fortune très ébranlée, essayer de la refaire en un moment où la vente des biens nationaux, le trafic des assignats, l'échange des effets et traites avec la pro- 
vince, l'étranger, etc., donnaient lieu à de nombreuses opérations où l'on pouvait chercher à faire son profit.

Cependant de cette série de lettres et papiers divers d'Emeric David (Bibliothèque de l'Arsenal, 5950, 5974, 5984, $5985,5982)$, où nous voyons le nom, Grégoire, sur des reçus, des traites, à propos de rendements de comptes et aussi, il faut le dire, de réclamations de co-participants mécontents, il n'apparaît pas que les frères aixois aient cette fois encore obtenu des bénéfices très rémunérateurs. Nous sommes même très portés à croire tout le contraire et à penser qu'à la mort de Dominique, survenue en 1802, son frère n'avait pas trouvé la richesse dans cette association, ni même retiré d'elle de quoi jouir d'une aisance suffisante.

Ce qui prouve qu'il n'avait jamais abandonné ses occupations favorites et la poursuite d'inventions, c'est que nous voyons, le troisième jour complémentaire de l'an huit de la République (1800), une demande adressée au : Citoyen Ministre de l'Intérieur, par le citoyen G. Grégoire, né à Aix, département des Bouches-du-Rhône, artiste fabriquant à métiers, patenté pour l'an VIII, sous le $n^{\circ} 144$, de Brevet de 15 ans, pour une découverte nouvelle, celle, dit-il en propres termes : " d'Etoffes ou tissus circulaires, plans et autres formes à " lisières ou à fonds inégaux, qu'il nomme "Tournoises ". " Lesdites étoffes applicables à beaucoup d'objets, princi" palement de parures et ornements pour hommes et pour " femmes, de même que pour meubles, dont je déclare ètre " l'inventeur et dont les moyens d'exécution et procédés sont " imprimés sur les plans et mémoires exécutifs ci-joints, " accompagnés d'échantillons provenant de ladite fabrica" tion et ce, en remplissant les formalités prescrites et ac" quittant la taxe et les droits fixés dans la loi réglementaire " du 25 mai 1791 ". (Archives nationales. F.22-999-1001) (1).

Nous ne nous étendrons pas en détail sur ces Tournoises, étoffes circulaires plus ingénieusement conçues qu'appelées à un succès pratique ; ces tissus, dont la description technique se trouve dans le Dictionnaire des Tissus de Bezon ( $t$. II,

(1) Pièce justif. $\mathrm{n}^{\circ} 8$. 
pages 27 et suivantes), étaient obtenus sur un métier disposé de telle sorte que les coups de trame se succédaient pour ainsi dire en éventail, toujours plus espacés sur une lisière que sur l'autre où, au contraire, ils étaient le plus serrés possible. L'idée était certes nouvelle; nous verrons que Grégoire la suivit avec persistance et obtint différentes récompenses officielles à ce propos.

Le Brevet en règle lui avait été délivré le 2 nivôse an $\mathrm{IX}$, et il fut "proclamé " par la minute d'arrêté qui existe aux Archives nationales AF IV, section moderne, à la date du 23 prairial an IX (1801) de la République une et indivisible, signée : Bonaparte (1).

Le 22 ventôse an X (1802), l'inventeur déposait une demande de certificat d'addition et perfectionnement et, dans le catalogue des Brevets de 1791 à 1827, Conservatoire des arts et métiers, mention est faite d'un deuxième Brevet de 15 ans pris le 2 nivôse an XIV, pour la fabrication des Tournoises, accordé également. Il habitait à ce moment, comme cela est indiquésur les pièces, rue de Paradis $n^{\circ} 20$, division Poissonnière.

C'est peu après qu'il eut la chance d'attirer à nouveau sur lui l'attention gouvernementale, car, à partir de l'année 1806 et dans toutes les pièces le concernant que nous avons pu retrouver, nous le voyons domicilié : 47, rue de Charonne, faubourg Saint-Antoine, à l'hôtel Vaucanson. Or, cet hôtel, précédemment Hôtel de Mortagne ou Mortaigne, au xvirI ${ }^{e}$, et propriété de la famille de ce nom, qui fut dessiné par l'architecte Delisle, avait eu pour habitant M. de Vaucanson, le célèbremécanicien, auteur des automates fameux. A sa mort, en 1782, une partie de ce qui constituait son cabinet réputé resta dans cet hôtel qu'il avait habité, pour constituer jusqu'à la Révolution avec Vandermonde pour directeur, sous le nom de Cabinet des Méchaniques du Roi, une sorte de musée, l'embryon du Conservatoire des Arts et Métiers actuel.L'hôtel avait été acquis par l'Etat en 1784 au Baron de Colins de Mortagne par les soins de M. de Tolozan, de l'administration

(1) Pièce justif. uค 9 . 
du commerce, et payé des deniers de la caisse du commerce. Nous voyons même, à ce sujet, qu'en 1790 une autre Administration voulant obtenir l'hôtel pour en faire une école gratuite de dessin, le commerce proteste (Arch. nationales, F12-107-108. Bureau du commerce). A la création du Conservatoire des Arts et Métiers, qui fut placé le 2 avril 1799 dans le Prieuré de Saint-Martin-des-Champs, l'hôtel ou maison Vaucanson devint une dépendance du Conservatoire, faisant partie des bâtiments civils, entretenus par l'Etat, sous l'administration immédiate du Ministre de l'Intérieur. Cet immeuble était, sousle Premier Empire, dans un profond état de délabrement, si l'on s'en rapporte aux fréquentes plaintes de ses habitants à ce propos (Arch. nationales F13-910. Lettres et documents divers).

Ainsi Grégoire écrit le 5 nivôse an XII (1), au Ministre de l'Intérieur qui était Chaptal et avait accordé à l'artiste l'appui de sa haute protection très éclairée, qui ne se démentit pas :

" Citoyen Ministre, vous m'avez fait espérer que vous " aggrandiriez le local que vous avez accordé à l'établis" sement des velours; vous vous rappelerez de même la " disposition oủ vous étiez d'accorder les réparations néces" saires dont quelques-unes sont très urgentes. " Et il demande la nomination d'un architecte au plus tôt pour faire les devis des réparations de première nécessité. Il demande aussi qu'on règle la division du logement avec les co-occupants de l'hôtel, les citoyens Mille, dit-il, qui, en réalité, étaient les frères Milne, inventeurs eux aussi, mais de mécaniques à carder et à filer le coton. Une certaine " rotonde " du milieu du bàtiment, indispensable pour les opérations "du velours ", dit Grégoire, paraît entre autres avoir été l'objet de compétitions entre les deux voisins ; mais le plus regrettable, c'est que l'argent manquait pour remettre ces locaux en bon état. L'architecte des bàtiments civils, Jallier, écrit, le 14 ventôse an XII, que le crédit alloué est trop faible pour réparer le mur et le logement du citoyen Gré-

(1) Pièce justif. no 10. 


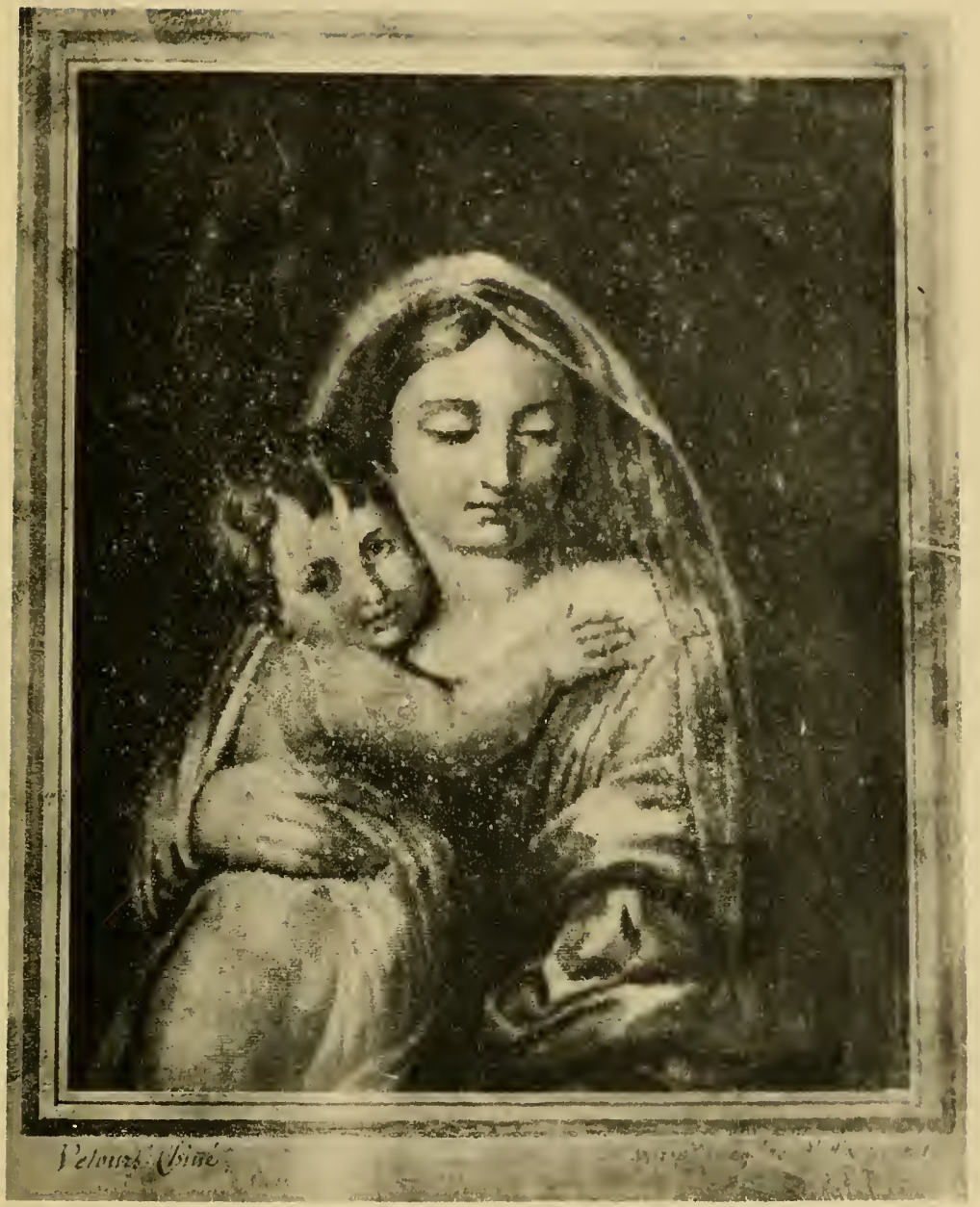

Vierge du Múusée d’Aix 

goire. Il fallut donc se contenter d'être logé dans une demeure que le temps avait bien épronvée; mais on était logé, c'était le principal, et puis on réclamait de temps à autre encore à l'Administration. En 1810, le 4 novembre, Milne frères et Grégoire sont d'accord pour écrire une lettre qu'ils signent tous deux, à l'architecte Gisors, qui avait à ce moment l'hòtel Vaucanson sous son inspection, pour lui demander de faire réparer la porte cochère qui ne pouvait s'ouvrir commodément dans l'hiver, ce qui avait des inconvénients et gênait, comme l'expliquent les intéressés: "les personnes de " distinction dont nous avons quelquelois la visite ". Lefeuve dit à ce propos dans ses Anciennes maisons de Paris, à l'article de l'hôtel Vaucanson, que la manufacture de Grégoire fut visitée en 1814 par l'Empereur d'Autriche, François II. Il y a même, dans ces correspondances (Arch. nat. F12 1284) échangées à propos de ces réparations d'un immeuble réellement en mauvais état, des détails à relever (1).

Grégoireécrit, le 30 mars 1816, pour une simple autorisation - il va avoir une famille d'ouvriers à loger ; - il est obligé de faire quelques divisions dans le logement, mais de les faire approuver, quoiqu" " il en fera les frais ».

Le 10 octobre 1818 , lettre pour une porte à percer, afin de donner un dégagement à une pièce, la seule où il puisse monter un métier d'essai pour divers tissus dont l'exécution doit rester secrète, même pour les ouvriers. Marque de prudence d'un inventeur qui vieillit et se plaint, le 22 septembre 1822, ayant 70 ans, de ne pouvoir faire du feu dans sa chambre faute de cheminée en état, et de ce que les eaux pluviales s'étendent sur le platond de l'atelier à tisser !

D'un autre côté, l'architecte Delaunay écrit toujours pour des travaux à exéculer à l'hôtel Vaucanson qu'ils devraient être supportés par M. Grégoire, " à moins qu'attendu son peu

(1) De nos jours l'hôtel Vaucanson, qui porte le $n^{0} 51$ de la rue de Charonne, est devenu, comme tant d autres demeures historiques, une maison de rapport envahie par le commerce parisien; on n'y fait plus de velours et on y vend des meubles. Une plaque sur le mur extérieur rappelle seulement que Vaucanson l'habita et y mourut. 
d'aisance et l'abandon qu'il vient de faire d'une partie des locaux qu'il occupait », on ne puisse imputer cette dépense sur des fonds d'entretien.

Et ce peu d'aisance constaté presque officiellement contredit l'affirmation que nous avons vue énoncée, que l'artiste bénéficiait aussi d'une pension; il est bien probable qu'il n'eut que le seul avantage de ce logement aux frais de l'Etat, avantage réel, consenti par contrat et à vic (1), et qui le demeura, malgré les gouvernements qui passèrent et se succédèrent et les changements administratifs (2), jusqu'à la mort de l'artiste, soit pendant nombre d'années, car il vécut jusqu'à un âge très avancé dans ce refuge calme et assuré de l'hôtel où un illustre prédécesseur avait construit ses "méchaniques ».

C'est là que dans une tranquillité laborieuse et patiente il dut combiner et exécuter les plus beaux de ses velours, pour mieux dire les plus marquants, car tous ont bien le même charme de facture. Il y fit de l'actualité au jour le jour avec des portraits comme ceux de Napoléon empereur, du Pape Pie VII, plus tard de Louis XVIII et de la duchesse d'Angoulême. En même temps, sans doute, s'efforçait-il d'arriver à ces velours en "grand " si difficiles à réussir, et n'obtenait pas, que nous sachions, de plus grandes dimensions que celle de la Marchande d'amours, d'après la reproduction de la célèbre peinture du musée de Naples qui mesure environ 33 centimètres carrés, pour la partie peinte.

On ne retrouve pas de traces de tentatives faites par lui pour faire transformer l'ancien privilège obtenu sous la Royauté pour ses velours en un brevet : il est très probable que la divulgation publique, nécessaire en pareil cas, de son

(1) Arch. nat. $F^{13}$ 1284. Lettre du Conseiller d'Etat au Directeur de l'Administration des bâtiments civils, 16 octobre 1835, d'où il ressort qu'à cette époque les occupants de l'hôtel, en plus de Grégoire et de la famille de Milne, mort sans ressources, étaient M. Mollard, de l'Académie des sciences, et un M. Dumas.

(2) L'immeuble avait été rendu aux Domaines par ordonnance du 6 février 1833. 
procédé n'était pas pour le séduire, et il s'en tint au brevet pris pour ses Tournoises, étoffes circulaires, qu'il ne négligeait pas de chercher à mettre en valeur et pour lesquelles il reçut une médaille de bronze en 1806.

Cependant il était arrivé sinon à la fortune, au moins à une honorable notoriété qui pouvait le consoler de bien des amertumes.

Il avait présenté à cette intéressante Société pour l'Encouragement à l'industrie nationale, fondée en $\mathbf{1 8 0 2}$ et qui existe encore de nos jours, "ses échantillons de velours imitant la " peinture, dont la perfection du tissu, la beauté du coloris " et la pureté du dessin ont été généralement admirés par " tous les membres sous les yeux desquels ils ont paru et qui " ont témoigné le désir qu’une branche aussi précieuse de " l'industrie française fùt justement encouragée. 》 (Moniteur de l'Empire, lundi 27 janvier 1806.) Ce fut Mérimée, le père du romancier, homme distingué par son talent de peintre, professeur de dessin à l'Ecole polytechnique et plus tard secrétaire perpétuel à l'Ecole des Beaux-Arts, qui lut à cette occasion à la Société d'Encouragement le rapport qu'il avait été chargé de faire au Ministre de l'Intérieur, sur les velours de Grégoire, conjointement avec MM. Contì et Miollard. Ce rapport est toutà fait élogieux et à l'honneur de l'artiste, il est presque dithyrambique; ainsi dit-il : "Pour tenter " une pareille entreprise, il ne suffisait pas de connaître à " fond les divers systèmes des machines à tisser, il fallait " encore être instruit des procédés de la teinture et pouvoir " assez bien peindre pour juger de l'exactitude d'une imita" tion; M. Grégoire possède ces divers talents, et ses succès " prouvent combien la réunion des arts et des sciences " exactes est favorable aux progrès de l'industrie, etc. "; et il conclut hardiment à la production facile de grands sujets pour l'ameublement, etc., que des commandes de l'Etat pouvaient encourager puissamment. A la suite de ce rapport, le Ministre de l'Intérieur adresse à Grégoire une lettre flatteuse (Moniteur de l'Empire, 27 janvier 1806), lui promettant l'appui officiel, en s'appuyant sur les conclusions des commissaires sus-nommés, et qui laissent plus sceptique sous 
le rapport des résultats à obtenir et obtenus; elle se termine par cette promesse un peu vaste :

" Si mes démarches produisent l'effet que je m'en suis " promis, vos travaux auront obtenu la récompense qu'ils " méritent et l'Etat se trouvera enrichi d'une nouvelle " branche de l'Industrie. " Après ce triomphe, moral tout au moins, ce sont encore des satisfactions du même ordre.

En juillet 1807, médaille d'argent de $1^{\text {re }}$ classe, décernée par la Société d'encouragement " à M. Grégoire à Paris, qui " est parvenu à tisser des tableaux en velours avec une cor" rection et une perfection qu'il ne paraissait pas possible " d'atteindre ». (Bull. de la Société d'encouragement, 6 année, juillet $1807, \mathrm{n}^{\circ}$ XXXVII.)

En 1813, des citations flatteuses à la séance de la Société, pour :

$1^{\circ}$ La Table des Couleurs dont le Ministre des manufactures et du commerce ordonne l'envoi aux manufactures impériales des tapisseries de la Couronne et au Conservatoire des arts et métiers de Paris et de Lyon.

Dans cette Table des Couleurs (1), publiée d'abord en feuilles de très grand format et qui fut suivie d'une explication, Grégoire avait disposé, en une sorte de cercle chromatique et classé dans un ordre résultant d'idées personnelles, 1350 teintes graduées, obtenues par le mélange et la combinaison des couleurs qu'il nomme primitives ou franches, complémentaires ou secondaires, etc.; elle avait alors une très réelle utilité pour des coloristes, et le mérite de l'inédit. (C'est postérieurement que Chevreul s'occupa de la même question.)

$2^{\circ}$ Un portrait de Sa Majesté l'Empereur exécuté en velours, " un des ouvrages les plus remarquables qui soient sortis " des ateliers de ce fabricant; on ne sait ce que l'on doit le " plus admirer dans ce portrait, ou de la parfaite ressem" blance, ou de la manière ingénieuse dont les couleurs y " sont mélangées ". (Bulletin de la Société d'encouragement, " $12^{\mathrm{e}}$ année, octobre 1813 , séance du 6 octobre.)

(1) Paris, de l'imprimerie de Gillé fils, 1812. 
En 1817, pour suivre l'ordre de date, article très élogieux dans le Moniteur universel du 29 juin 1817 sur les velours de Grégoire et qui nous prouve que les rapports n'avaient pas cessé entre les amis d'autrelois, car il est d'Emeric David, consacré maintenant crilique d'art, - et une lettre de l'artiste aixois à son compatriote (Arsenal, lettres et papiers divers, Emeric David, 5975, $n^{\circ} 94$ ) nous en donne le remerciement qu'il lui fit, avec l'invite intéresséeà parler par avance de sa Table des Couleurs qu'il est en train de faire rééditer en un plus petit format. (In-12 raisin, Bibl. nat.)

Le 18 avril 1821, à la séance générale de la Société d'encouragement (Bulletin de la Société d'encouragement, $n^{\circ}$ CCII, avril 1821), on s'occupe, avec une attention particulière et des éloges, des étoffes circulaires, fabriquées par M. Grégoire, et d'un Tableau de fleurs, d'après Van Huysum, exécuté sur velours, qui est unanimement trouvé « d'une rare perfection "),

En 1823, Grégoire est exposant, à l'Exposition au Louvre, des produits de l'industrie française, et obtient avec ses velours (dans la $5^{\mathrm{e}}$ division, Beaux-Arts), un rappel de médaille d'argent décernée à une exposition précédente en 1819. (Monileur universel, 25 octobre 1823.) Il y a, dans le même journal du 26 septembre 1823 , une notice sur ces ouvrages, (peut-être inspirée).

Enfin, dernière date que nous trouvons à mentionner: en 1839, Grégoire publie ou réédite encore plusieurs opuscules :

$1^{\circ}$ Théorie des Couleurs, contenant explication de la Table des Couleurs, expériences et observations physiques et théoriques sur les couleurs, moyens de produire soi-mème les couleurs, méthode de noter les couleurs et de les exprimer par des nombres. Avec figures coloriées, à Paris, chez l'auteur, hôtel Vaucanson, 47, rue de Charonne, et chez Brunot-Labbe, quai des GrandsAugustins, $n^{\circ} 33$, - de l'imprimerie de Gillé (format in-4, Bibl. du Conservatoire des Arts et Métiers). Une autre édition porte chez l'auteur, rue de Charonne, 47, et chez Bachelier, imprimeur-libraire de l'Ecole polytechnique et du Bureau des Longitudes, 55, quai des Augustins (Bibl. Montagne de Firmont). 
$2^{\circ}$ Expériences primitives à l'usage du système des trois couleurs primitives, chez Bachelier (Société d'encouragement ${ }^{2}$ 2675).

$3^{\circ}$ Expériences prismatiques à l'appui du système des trois couleurs primitives, chez Bachelier (Société d'encouragement A 2675).

De lui sont encore: des Tableaux numériques des Couleurs:

$1^{\circ}$ Pour l'évaluation des teintes.

$2^{\circ}$ Pour l'évaluation des tons; cet opuscule, qui fait suite à l'explication de la Table des Couleur's, est sans date de publication, édité par Brunot-Labbe (Société d'enc. A 2885).

L'homme qui toute sa vie avait aimé les recherches guidées par la réflexion, se délassait sur ses vieux jours du travail du manufacturier pratique par celui du théoricien plus détaché des réalisations. $I l$ avait $\$ \&$ ans et restait bientôt presque seul de la nombreuse famille dont il avait fait partie : son frère cadet Paul, l'infirme et sans doute toujours son commensal, allait mourir avant lui, le 7 juin 1842. Après une vie si longue et dont nous connaissons si peu des faits intimes et de ce qui pourrait nous déceler quelque chose de lui-même, autre que ce que nous pouvons en penser daprès son effort, ses aspirations et les marques d'un esprit remarquablement doué qui se conserva jusqu'à la fin, après bien des épreuves, des agitations, ayant été contemporain d'événements qui changèrent la face du monde, sans que rien ait pu modifier sa foi en son œuvre et ce goût passionné d'un idéal artistique uni et comme " tissé » avec la réalisation pratique, il mourut, célibataire, comme il avait vécu, le 12 mai 1846 (1), en cet hôtel Vaucanson qu'il n'avait plus quitté.

N'eut-il pas le droit de se dire « qu'il arait fait ce qu'il avait pu ? »

(1) Pièce justif. $n^{0} 11$. 


\section{LE PROCÉDQE DE GRÉGOIRE}

Quel était donc le procédé au moyen duquel Grégoire obtenait ses velours peints? Nous avons vu, par les divers documents cités concernant le privilège qui lui fut octroyé par arrèt rendu le 12 juillet 1788, que l'une des conditions imposées à l'inventeur était de donner par écrit son procédé, dont une copie devait revenir au bureau de l'Administration du commerce, " pour le dit procédé être rendu public à l'expiration des 15 années ». Il aurait été d'un grand intérêt de retrouver ce précieux document, mais nos recherches dans ce but sont restées vaines jusqu'ici ; d'autre part, nous savons par un passage d'une lettre (1) d'une nièce de Grégoire, $\mathrm{M}^{\mathrm{m}}$ Duguet, fille de son frère Dominique, que peu de jours avant sa mort, son oncle avait brûlé tous les papiers concernant son invention des velours. Acte réfléchi, puisque, dit-elle, il avait conservé tonte sa connaissance, compréhensible jusqu'à un certain point chez un inventeur jaloux de ne pas pouvoir au moins être égalé, et si regrettable cependant ! Mais il faut bien dire que cette invention, incontestable en elle-mème au point de vue idée et priorité, reposait plus sur un ingénieux tour de main, uni à un ensemble de conditions pratiques réalisées avec patience et attention, que sur un mystère destiné à rester impénétrable à des imitateurs au courant des choses du tissage et à même de se livrer à des essais longs et certainement coûteux. Il y en eut donc et, en nous réservant de parler plus tard de tous ceux que nous connaissons, nous mentionnerons d'abord

(1) Communiquée par M. Montagne de Firmont. 
un M. Spoerlin, de Vienne, qui présenta à la Société industrielle de Mulhouse (Bulletin de la Société, t. I ${ }^{\text {er }}$ ) une relation détaillée, sous forme de notice, de ses travaux pour produire des velours comme ceux de Grégoire. Ce document est considéré comme officiel pour ainsi dire par Bezon (Dictionnaire des Tissus, t. VI, p. 62 et s.), qui lui a emprunté la description qu'il donne de la façon de procéder de Grégoire, reconstituée par l'expérience. En limitant au minimum l'emploi des termes techniques, nous nous sommes inspiré de cette même description pour tâcher d'être clair dans ce qui va suivre.

Le velours de soie coupé étant un tissu formé de deux chaînes (1) et de la trame, l'une des chaînes, dite toile, fait le fond de l'étoffe avec cette trame, et l'autre chaine, dite poil, travaille, selon l'expression consacrée, de telle sorte qu'elle vient à tour de rôle, d'abord s'entrelacer au tissu de fond ou support du velours, et aussi se replier au-dessus de ce fond, sur une série de petites tiges appelées fers, métalliques le plus généralement, que l'ouvrier passe successivement sous ces fils de poil dans le sens même de la trame, ces fils de poil formant, par suite, autant de petites bouclettes serrées les unes à côté des autres sur ces fers. Au fur et à mesure du tissage, et quand un certain nombre de ces fers ont été passés, l'ouvrier achève le velours en coupant avec un instrument spécial appelé rabot ou pince, soit une lame d'acier très effilée dirigée par une rainure que le fer porte à sa partie supérieure, ces bouclettes en deux parties; celles-ci n'étant plus retenues que d'un côté à leur base dans le tissu de fond où elles sont prises, forment de l'autre côté toute une série de petites houppettes soyeuses, dont la juxtaposition, étant donné leur nombre, compose la partie veloutée du tissu terminé.

Un dessin très grossi de ce travail des fils dans le velours nous fera mieux comprendre. (Voir fig. 1).

C'était donc sur les fils de la chaîne de poil de ses velours

(1) On entend par chaîne l'ensemble des filis disposés dans la longueur sur le métier. 


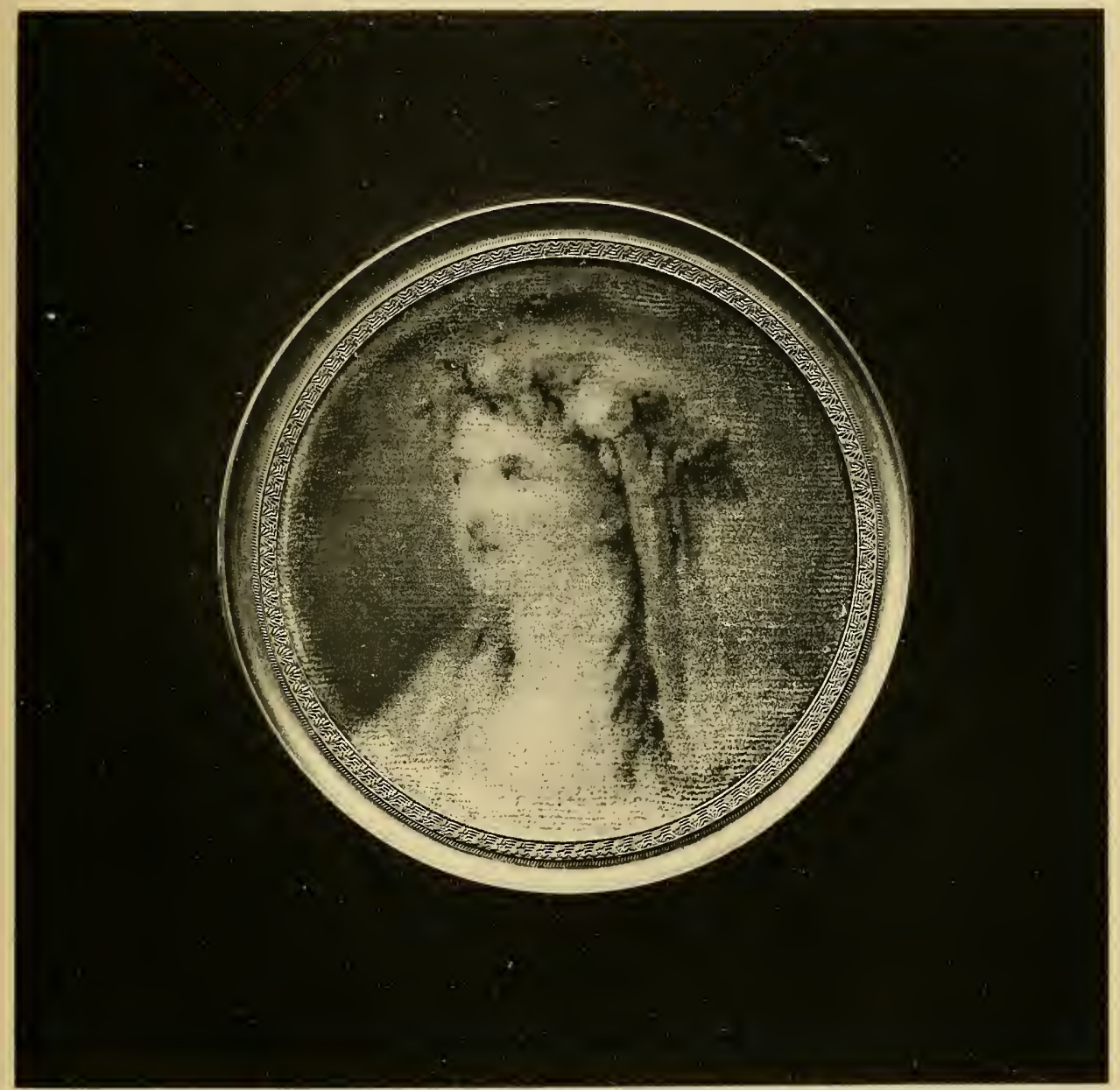

Phototypie Berthaud

Tête de Jeune Fille

(d'après GREUZE) 

que Grégoire était obligé de peindre les différents effets colorés des sujets et tableaux qu'il voulait reproduire, s'inspirant, comme nous l'avons dit, de la méthode du chinage, procédé de teinture partielle et successive des fils de soie de la chaine également, avec toute une technique de repérage, pour arriver à placer les couleurs sur le tissu comme elles l'étaient sur le modèle, esquisse ou carton. Ce procédé si délicat et complètement perdu de nos jours, au moins pour les

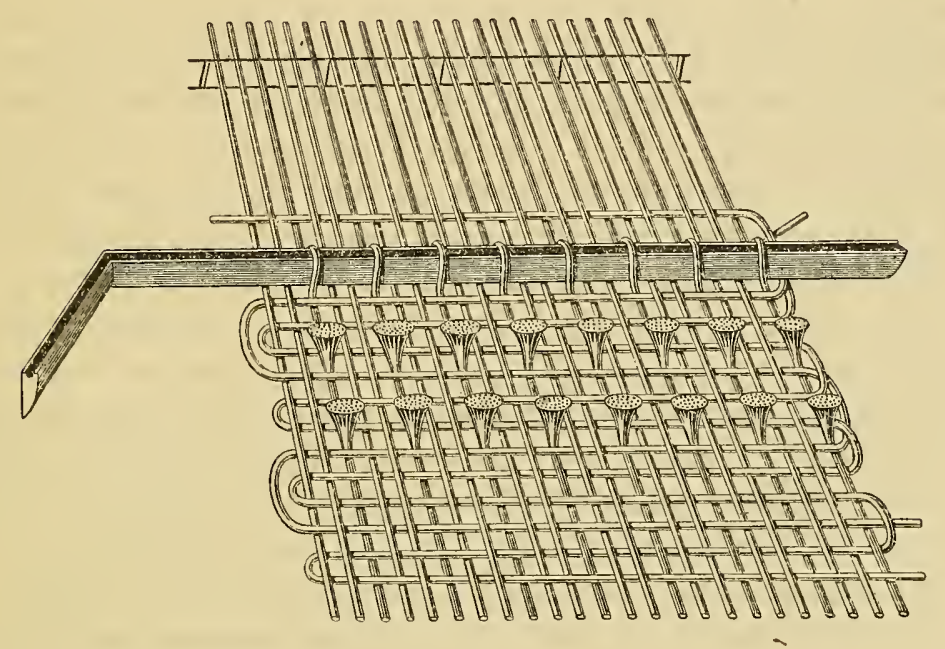

Fig. 1.

dessins à grands rapports, permettait d'obtenir sur des tissus, taffetas, satins et même velours, une décoration cerlainement très intéressante et même étonnamment variée, mais manquant totalement du modelé et des coloris fondus et ombrés que seul le pinceau pouvait donner.

Pour établir cette chaìne de poil destinée à supporter la peinture, il fallait non seulement en préparer les fils de façon que la soie pût être pénétrée convenablement par les colorants, ceci n'était rien, mais surtoul il était indispensable de tenir le plus grand comple de la question de réduction des proportions, due au travail spécial du velours. C'est là le point capital du système qui a tellement gêné 
Grégoire pour arriver à des velours " en grand " et un de ceux qui ont rendu plus difficile la tâche de ses copistes.

Comme nous l'avons dit, la chaîne de poil du velours vient s enrouler pour ainsi dire continuellement dans le tissage sur la série des fers ; par suite de ce trajet si constamment contourné, sinusoïdal pour être exact, elle subit une diminution de longueur considérable, puisque ce retrait, ou embuvage, comme disent les spécialistes, varie selon le velours et la hauteur des fers employés, de 5 à 7 pour 1 ; c'est-à-dire qu'avec 5 ou 7 mètres de longueur des fils de chaîne on obtient 1 mètre de velours fabriqué. Supposons que le velours soit de la proporlion de 5 , il faudra donc par 120 centimètres de velours par exemple: 6 mètres de poil, et rien que pour un tableau de 33 centimètres carrés, une chaîne de 1 mètre 65 de long. On roit tout de suite la difficulté de s'attaquer à des dessins de grandes proportions qu'il faut augmenter tellement encore, soit de 5 à 7 fois, d'autant que se présente en même temps une autre complication: pour un velours de 33 centimètres carrés il faut une chaine de 1 mètre 65 de long sur 33 de large. Mais quel artiste aurait pu entreprendre de peindre sur une surface aussi allongée, sans craindre que le rapprochement postérieur au cinquième ne produisît un résultat déplorable? Ne pouvant donc peindre sur une surface aussi disproportionnée, on se voit obligé d'écarter les fils de la chaîne à la même largeur, c'est-à-dire à 1 mètre 65 , pour avoir un carré parfait; mais les fils nécessaires pour obtenir un velours de 33 centimètres de large, écartés les uns des autres à une distance cinq fois plus grande, ne formeraient plus qu'une sorte de canevas tellement mince et ajouré qu'il n'y aurait pas possibilité d'y tracer la moindre chose. Grégoire résolut la difficulté en multipliant les chaînes, en en mettant quatre ou cinq ou six ensemble pour former une masse de fils quatre, cinq ou six fois plus épaisse. Ce moyen présentait, en outre, l'avantage de peindre quatre, ou cinq, ou six tableaux à la fois, qui devaient être séparés, après, d'une façon parfaitement possible pratiquement, et rigoureuse, de telle sorte que chacun était la parfaite copie de l'autre. Ceci nous explique également pourquoi l'on trouve 
des répliques des œuvres de Grégoire aussi identiques.

Ce n'était pas tout, il fallait encore peindre sur un ensemble de fils disposés dans la largeur convenable, mais que rien ne retenait entre eux; quelque tendue quait pu être cette chaîne, à chaque coup de pinceau les fils se seraient déplacés et par leur écartement auraient défiguré le dessin à tel point que l'on n'aurait plus pu s'y reconnaitre. Grégoire plaçait donc ces fils sur un premier métier et les liait par une légère trame pour en former un tissu taffetas (1) très mince, que l'on pouvait dans cet état tendre dans tous les sens en le plaçant sur un châssis. Naturellement la chaîne pouvait avoir une plus grande longueur que celle nécessitée par un seul tableau, afin d'exécuter une série de tableaux en les divisant sur la longueur totale, et en prenant soin à cet effet de laisser entre eux assez d'intervalle pour les séparer et de ménager aux deux bouts une longueur suffisante pour fixer la chaine sur le métier. Il fallait aussi, pour pouvoir séparer régulièrement et sans peine, le moment venu, les chaînes peintes ensemble, faire entrer dans le taffetas du premier tissage le nombre de cordons nécessaire pour former, deux par deux, les envergeures (2) de chaque chaîne destinée à ètre mise à son tour sur le métier de velours (3).

Afin de pouvoir, une fois les opérations de peinture terminées, retirer facilement la première trame devenue inutile, on formait sur les deux bords une sorte de lisière moyen-

(1) On a dit que Grégoire employait pour ce tissu préparatoire l'armure satin, mais rien ne nous semble justifier cette théorie contraire à tout ce qui se fait de nos jours dans la pratique de l'impression sur chaine. Bezon (Diclionnaire des Tissus, t. II, p. 106) dit : " M. Reybaud a aussi plusieurs " échantillons de tissus Grégoire fond taffetas destinés à être tissés " une seconde fois en velours. Ces taffetas sont tissés à la réduction de « 80 coups au centimètre. Une aussi forte réduction servait à maintenir " la chaîne pour éviter tout dérangement. ) Bezon nous parait faire autorité.

(2) Une chaîne est envergée quand elle est disposée de telle sorte que les fils pairs puissent être distingués immédiatement des fils impairs, dispositif iudispensable pour le tissage, et assuré par des verges ou tiges de bois arrondies, sur lesquelles sont passés ces fils.

(3) Soit en remettant suivi sur 8 lisses, s'il y a un compte de 4 chaînes et en prenant les lisses nos 1 et 2 pour l'envergeure d'un 1er tableau, les lisses 3 et 4 pour celle du $2^{3}$, et ainsi de suite. 
nant une ficelle écartée à peu près de deux centimètres des derniers fils à droite et à gauche de la chaîne. Cette ficelle servait encore pour tendre l'étoffe sur le châssis à peindre.

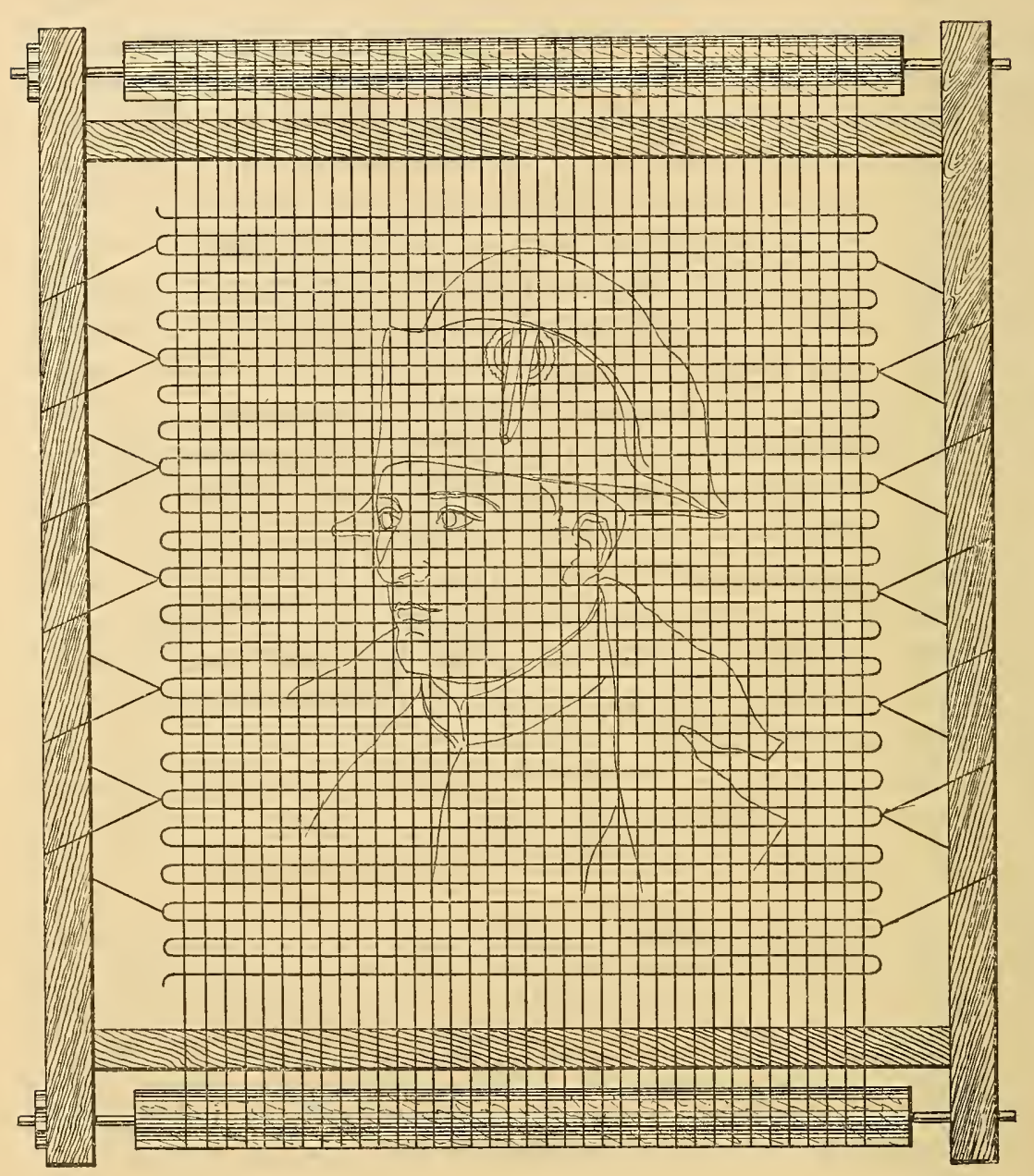

FIG. 2.

Celui-ci, constituant le chevalet du peintre, était de bois assez fort et un peu plus grand que le tableau. A deux de ses extrémités opposées étaient fixés des rouleaux de bois, ou ensouples, munis chacun d'un encliquetage. Ces ensouples 
servaient à enrouler et à tendre le tissu ; sur les deux côtés on le tendait au moyen des lisières à ficelle, de la même manière que l'on tend les étoffes sur le tambour à broder. (Le schéma ci-contre donme une idée de la disposition adoptée.)

Dans toutes ces manipulations il fallait avoir le plus grand soin que l'étoffe fût toujours tenue parfaitement d'équerre et prendre garde de ne pas déchirer ou étirer les fils, car tous les défauts devaient paraître sur le velours terminé.

Le châssis une fois bien ainsi préparé, il s'agissait de peindre; on pouvait évidemment se guider pour le report des grandes lignes du dessin sur les fils de soie, en appliquant derrière l'étofle, à l'exemple du carton dans le métier de tapisserie à basse lice, un papier sur lequel on avait tracé les contours du modèle un peu vigoureusement à l'encre de Chine, lesquels vus par transparence pouvaient être calqués avec un pinceau et une couleur légère. Mais pour tout le reste et l'achèvement de la peinture, si Grégoire a excellé avec tant de supériorité, c'est que d'abord il était dessinateur lui-même, ayant de plus l'aide de son frère Paul, l'artiste sourd et muet dont la part de collaboration dans les œuvres fraternelles peut avoir été très importante. Que ce soit à l'un ou à l'autre qu'il faille en attribuer le mérite, on voit très bien que les velours Grégoire ne montrent aucune faute ni défaillance du dessin; de plus, sans doute par toute une longue série de tâtonnements, il était arrivé, chose des plus importantes, à posséder une palette de coloris qui était son plus réel secret et qu'on a mal imitée. M. Spœrlin donne bien toute une liste de substances colorantes empruntées de préférence au règne végétal, comme devait l'être sans aucun doute celles qu'employait Grégoire; mais, n’ayant pas été à même de rien voir de ces productions de M. Spœrlin, nous ne pouvons pas avoir une opinion sur leur valeur. Quant à celles d'imitateurs plus récents, elles donnent bien tort à la chimie tinctoriale moderne pour cet emploi.

Enfin, dans la façon de préparer ces couleurs, de les appliquer et aussi sans doute de les fixer, il y avait tout un art habile et patient qui nous rend encore plus sceptique sur l'extension pratique et commerciale qu'avait rêvée l'artiste 
aixois, même en ne tenant pas compte de toutes les dextérités et de tous les soins de tissage qu'il fallait avoir aux opérations successives.

Ainsi, notamment, M. Spœrlin explique qu'il faut que la teinte qu'on applique traverse bien le fil ; il faut aussi éviter les frottés à pinceau demi-sec, autrement la couleur ne se trouverait que sur la superficie du fil, lequel étant coupé et présentant son épaisseur qui serait restée blanche, ne donnerait qu'une nuance incertaine et faible. Pour cette même raison, on doit commencer par les tons les plus vigoureux et travailler du foncé au clair, en ménageant les lumières. Et ce sera tout un apprentissage que d'arriver à bien, surtout pour les teintes claires, et pour toutes en général, car on fait du velours, et la soie une fois coupée donne, comme on sait, vue par sa tranche, un ton trois ou quatre fois plus foncé que celui du fil vu dans sa longueur.

Il faut encore faire attention de ne point surcharger le fil de couleur, ce qui le ferait déteindre à son passage au peigne(1), et alors les parties blanches ou claires des fils se saliraient en passant à travers ce peigne, etc., etc.

Enfin, toutes ces opérations bien et heureusement conduites, restait encore le second tissage, celui du velours; et, pour cela, nécessité d'enlever, avec toutes précautions, la chaîne peinte de son châssis, de séparer les unes des autres les diverses chaînes assemblées pour la peinture et en enlever en même temps la première trame, travaux délicats même pour des " canuts » expérimentés, étant donné qu'il ne fallait rien déranger à la position respective des fils entre eux dans une même chaîne, sous peine de dénaturer le dessin ou de produire des défauts. Après, il fallait encore placer successivement chaque chaîne, isolée, sur un métier de velours préparé avec sa chaîne de toile, en la ramenant par le moyen du peigne à la largeur cherchée, le travail du velours devant automatiquement réduire la longueur à celle voulue

(1) Instrument du métier destiné à maiutenir les fils de la chaîne à l'écartement choisi, par ses dents métalliques dans lesquelles ils sont disposés, à intervalle fixe. 
pour que les lignes du dessin soient à leurs justes proportions; enfin confier le tissage à un ouvrier habile à cette étoffe (Grégoire avait fait venir les siens de Lyon), qui demande une longue pratique pour être obtenue sans défaut. Il fallait aussi calculer la hauteur des fers à velours, Grégoire en employait de très bas (1), enfin tramer avec une soie blanche, comme devaient l'être également les fils de la chaîne de toile ou de fond, pour laisser toute leur fraîcheur aux tons clairs du tableau. On constatera facilement l'exactitude de ce détail sur les velours Grégoire, qui sont généralement et doivent être encadrés entre deux verres et ne perdent rien à être vus par transparence, contre le jour,

On peut se représenter, d'après cet exposé, combien dans son ensemble le travail de ces velours exigeait de soins, de précautions de toutes sortes et d'une habileté due à la pratique. En somme, pas de secret à proprement parler, si ce n'est pour la composition des couleurs employées, pour peindre, pas d'opération inconnue, mais un tour de main très ingénieux appliqué avec autant de précision et de minutie dans le tissage que de recherche dans la peinture.

Mais on voit aussi, nous revenons sur ce point, les côtés impraticables de l'obtention de grands sujets, aṽec la nécessité inéluctable d'amplifier considérablement les dimensions du modèle à reproduire en velours ; soit d'opérer. par exemple, sur deux à trois mètres carrés pour en avoir le quart, soit 0,50 $\times 0,50$ en fin de compte, - ceci s'accompagnant de complications ou d'impossibilités, d'abord pour le premier tissage, ensuite pour la peinture, sur des châssis d'une telle importance, difficiles à manier commodément, sans qu'il en résulte des risques encore plus grands d'insuccès, etc., etc., dans la suite des opérations.

On se rend compte, enfin, que forcément le prix de revient de semblables velours devait être élevé, en raison d'abord du temps nécessaire pour toutes les opérations, et n'attribuerait-on même au travail du peintre que la valeur du salaire d'un simple copiste, ce qui ne saurait cependant

(1) Pour réduire au minimum l'allongement primitif nécessaire. 
être le cas, car nous avons fait ressortir le caractère véritablement artistique de l'exécution de la peinture, auquel est dù, pour une très grande part, le mérite de ces tableaux.

Au reste Grégoire, en plus des portraits dont nous avons parlé, s'est attaché à la reproduction d'œuvres de valeur et célèbres ; ainsi il a traité d'après Raphaël des sujets religieux : Vierge à la chaise, etc.; d'après le même encore, il a pris pour modèles cette série si remarquable des Heures, qui eut l'avantage de lui fournir un genre décoratif charmant en même temps que tout à fait dans le goût de son époque, où le style de Ponıéi était tellement en honneur ; et nous savons qu'il visait avec ses velours à des emplois comme ceux de l'ameublement, sièges, écrans, pour lesquels sous l'Empire on fit du reste des impressions directes sur velours de coton et de soie, - fleurs, oiseaux, sujets pompéiens, etc. ; on peut en voir des spécimens fort curieux au Garde-Meuble National.

Toujours dans le même ordre d'idées, il exécuta son magnifique velours d'après la Marchande d'Amours, la célèbre peinture du musée de Naples, imitée librement par Vien, gravée par Beauvalet et Réveil.

Probablement pour orner ces objets, boites, bibelots, etc., mis en vente au Palais-Royal, il s'inspira de Greuze pour tirer de son œuvre quelques médaillons du plus grand charme.

Enfin il peignit des fleurs, comme nous l'avons vu, d'après Van Huysum, et on peut dire que dans à peu près tout ce qu'il a traité on retrouve les mêmes caractéristiques de goût dans l'arrangement, le dessin et le coloris.

A ce dernier point de vue cependant, il est à remarquer que les œuvres de l'artiste, dans leur état actuel, présentent d'assez notables différences entre elles. Il faut évidemment tenir compte de leur inégal degré de conservation et des altérations causées par l'humidité, la poussière, la lumière trop vive, etc.; mais l'exécution elle-même si délicate de la peinture a pu présenter des insuccès même partiels, alors qu'on ne pouvait apprécier la justesse des tons qu'une fois le velours fini et coupé et qu'aucune retouiche n'était plus pos- 


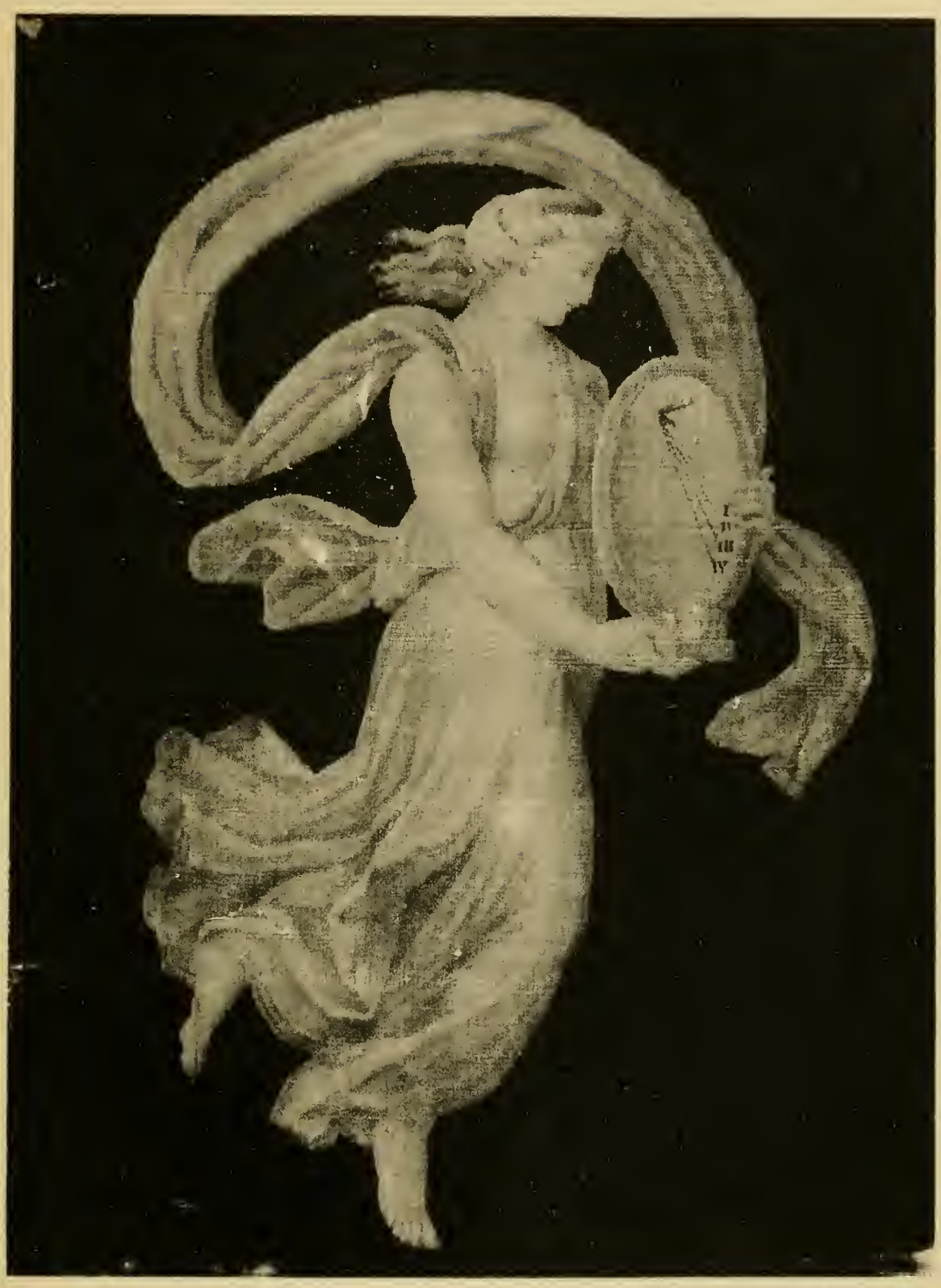

Phototypie Berthand

Heure d'après Raphael 

sible. Ainsi dans certains tableaux, de fleurs par exemple, les teintes claires ont presque disparu et ne s'harmonisent pas avec le reste de la coloration ; les fonds blancs, du reste, paraissent n'avoir pas donné un effet flatteur : dans ses portraits l'artiste employa de préférence des fonds neutres ou foncés, avec des teintes parfois un peu plates mais plutôt vives dans l'ensemble. Le portrait de Pie VII offre un très heureux exemple de gammes de rouges et de roses un peu vineux, dont Grégoire usa fréquemment d'ailleurs.

Les petits sujets : Portrait de Louis XVI, médaillons genre Greuze, sont nués avec une finesse et une délicatesse du meilleur effet ; mais là où l'artiste nous semble avoir atteint la plus grande perfection, c'est dans l'exécution des Heures et de la Marchande d'Amours, sujets traités sur fond noir, les uns dans des ententes de tons camaïeux très doux, les autres avec toute la richesse de tons variẻs, nombreux, mais parfaitement harmonisés et fondus. C'est là vraiment ce qu'il fit d'inimitable.

Notons encore que le velours de la Madone à l'Enfant, du musée d'Aix, qui est dans des tons de gravure sur fond jadis blanc, porte au bas, particularité remarquable, l'inscription tissée avec le reste du tableau : "Velours chiné, Gaspard Grégoire d'Aix, Inv. " C'est le seul que nous ayons vu avec cette signature, et il nous paraît être une des œuvres du début.

Enfin, un autre velours, tête de femme, an Musée des tissus de Lyon, offre aussi cette autre particularité, unique à notre connaissance, d'avoir été fait en velours frisé ou épinglé, c'est-à-dire avec le poil non coupé, ce qui lui donne un aspect spécial. 


\section{QUELQUES VELOURS GRÉGOIRE}

Ne voyant pas pour le moment la possibilité d'établir une nomenclature certaine et complète de tous les sujets que Grégoire a pu exécuter en velours peint, en obtenant, comme nous l'avons dit du reste, nécessairement plusieurs répliques du même tableau, nous nous bornerons à la mention et description succincte de ceux ci-dessous dont la plupart sont du reste à la disposition du public :

\section{AU MUSÉE D'AIX EN PROVENCE.}

Sous le $n^{\circ} 603$ : Vierge à l'Enfant, mesurant $0,20 \quad 0,16$, figure à mi-corps, traitée dans des tons de gravure, de bistre à brun presque noir sur fond blanc (devenu jaunâtre), avec l'inscription tissée au bas : "Velours chiné, Gaspard Grégoire d'Aix, Inv. »

$\mathrm{N}^{\circ} 602$. - Portrait de Napoléon $\mathrm{I}^{\mathrm{er}}$, couronné de lauriers, $0,22 \times 0,17$.

Ces deux velours ont été donnés au Musée par l'auteur lui-même.

No 604. - Sujet, catalogué Léda, en réalité d'après une Heure de Raphaël, la VI de la nuit, femme drapée à l'antique, ailée, tenant un cygne, environ $0,22 \times 0,30$. Sur fond noir, coloris très finement nué.

Don de Mme Duguet, nièce de Grégoire.

COLLECTION DE M. MONTAGNE DE FIRMONT, A AIX.

La Vierge à la Chaise, d'après Raphaël, sur fond grenat foncé, mesurant $0,25 \times 0,30$.

Bouquet de fleurs, posé sur une table à côté d'un vase, fond grenat, $0,25 \times 0,30$. 
Christ en croix, sur fond noir, $0,18 \times 0,27$.

Fruits sur une table, fond grenat, $0,19 \times 0,22$.

Sujet de Pastorale, trois personnages et brebis au pied d'un rocher, traité en camaïeux roses et rouges, $0,16 \times 0,19$.

Médaillon ovale, diamètres $0,101 / 2 \times 0,12$, tête de jeune fille d'après Greuze.

Fleurs débordant d'une corbeille, format miniature, médaillon rond, diamètre $0,61 / 2$.

\section{AU MUSÉE DE MARSEILLE.}

Tête de Bacchante, petit médaillon rond, legs du $\mathrm{D}^{\mathrm{r}}$ Bucquet.

AU MUSÉE HISTORIQUE DES TISSUS DE LYON.

No 27.095. - Christ en croix (déjà cité) tableau rectangulaire, teintes qui ont pâli sur fond noir.

No 27.993. - Portrait de Bonaparte en uniforme vert avec le chapeau, - rectangulaire.

Sans $n^{\circ s}$. - Petits sujets en médaillons ronds ou ovales dans le goût mythologique ou pastoral.

No 1006. - Tête de jeune homme d'après Greuze, médaillon rond, nuances effacées, avec une réplique du même, un peu plus petit, tons beaucoup plus colorés.

No 1006. - Tête de jeune fille avec un bonnet, d'après Greuze, médaillon rond.

Sans $n^{\circ}$. - Autre tête de jeune fille, d'après Greuze, médaillon rond, un peu plus grand que le précédent.

Sans $n^{\circ}$. - Tableau de fleurs disposées en bouquets droits, colorations vives, - rectangulaire.

Sans $n^{\circ}$. - Autre tableau de fleurs, roses dans un verre d'eau, - rectangulaire.

Ces deux velours, dont l'un ne porte aucune indication et l'autre est marqué "Velours Grégoire ", ne sont cependant que des imitations faites postérieurement, comme l'indiqueraient seulement le genre du dessin et les tons de la peinture, s'il n'était établi qu'ils ont été exécutés par un dessinateur de fabrique, M. Garin. 
Sans $n^{\circ}$. - Un portrait de Louis XVI, d'une excellente exécution, avec des tons restés très frais : petit médaillon ovale.

Sans $\mathrm{n}^{\circ}$. - Bouquet de fleurs, traité en miniature : très petit médaillon rond.

No 996. - Portrait de Napoléon I ${ }^{\text {er }}$. Empereur lauré avec le manteau impérial (comme dans le Couronnement, par David) ; rectangulaire, environ $0,22 \times 0,17$.

No 997. - Portrait du Pape Pie VII, d'après David : rectangulaire, même proportion que le précédent.

(Le même existe au musée des Arts décoratfs.)

No 26270. - Sujet d'après la série des Heures de Raphaël, la $I^{e}$ de la nuit : femme drapée à l'antique, tenant un oiseau, fond noir, coloris nué; rectangulaire, environ $0,22 \times 0,30$.

Sans $n^{\circ}$. - Idem, d'après la $V^{e}$ Heure de la nuit : femme drapée à l'antique, ailée, élevant au-dessus de sa tête un vase dont le contenu se répand, fond noir, coloris nué; rectangulaire, environ $0,27 \times 0,30$.

Sans $\mathrm{n}^{\circ}$. - Idem d'après la I ${ }^{\text {re }}$ Heure de la nuit : femme drapée à l'antique, portant dans une main une chouette, fond noir, coloris nué, tons atténués et pâlis, rectangulaire, environ $0,27 \times 0,30$.

Sans $\mathrm{n}^{0}$. - Idem d'après la Ire Heure du jour : femme drapée à l'antique, portant un flambeau, fond noir, coloris nué ; rectangulaire, environ $0,27 \times 0,30$.

No 26270. - Idem d'après la II ${ }^{\mathrm{e}}$ Heure de la nuit : femme drapée à l'antique, élevant d'une main un sablier, fond noir, coloris nué, pâle ; rectangulaire, environ $0,27 \times 0,30$.

No 1003. - Sujet de mêmeinspiration, mais plus modifiée : femme drapée à l'antique, portant des vases, fond noir, coloris nué; rectangulaire, environ $0,27 \times 0,30$.

Sans $\mathrm{n}^{0}$. - Idem, femme drapée à l'antique, portant d'une main un plat avec des fruits, de l'autre une aiguière, fond noir, coloris traité en tons camaïeux roses ; rectangulaire, environ $0,27 \times 0,30$.

$N^{\circ} 1004$. - Vierge à la chaise, d'après Raphaël, fond bistre, coloris nué, encadrement ovale. 
No 1004. - Vierge à l'Enfant d'après Raphaël, fond bistre, coloris nué.

Sans $\mathbf{n}^{\circ}$. - Madone d'après Raphaël, fond bistre, coloris assez accentué ; rectangulaire, environ $0.17 \times 0.20$.

Sans n". - Sujet religieux, Saint considérant un globe surmonté d'une Croix, fond bistre, coloris accentué ; rectangulaire, environ $0,17 \times 0,20$.

Sans $n^{\circ}$. - Portrait de la duchesse d'Angoulême ; rectangulaire, environ $0,17 \times 0,20$.

$\mathrm{N}^{\circ} 1000$. Portrait de Louis XVIII ; rectangulaire, environ 0,17 ; 0,20 .

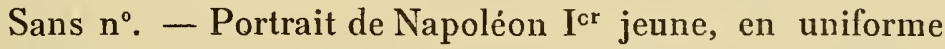
de général.

Sans $\mathrm{n}^{\circ}$. - Portrait d'un personnage en uniforme rouge brodé de feuilles de chêne.

Sans $n^{\circ}$. - La Marchande d'Amours, d'après la peinture de Pompéi, en deux parties ; dans celle du dessus, d'environ $0,40 \times 0,50$, femme drapée à l'antique, tenant un Amour, avec à ses pieds une cage renfermant un autre Amour ; fond noir, coloris parfaitement nué. Dans le même encadrement est rajustée une deuxième partie en soubassement, d'environ $0,28 \times 0,50$, formant, avec encadrement uni noir, un cartouche fond blanc dans lequel sont disposés des Amours et des attributs, très finement traités et nués. (Une réplique de ce même sujet pour la partie du haut existe en plus petit au Conservatoire des Arts et Métiers à Paris.)

№ 998. - Tête de femme, petit médaillon ovale, exécuté en velours frisé.

Sans $n^{\circ}$. - Branche de pommier en fleurs, sur fond blanc; rectangulaire, assez grand.

Sans $\mathrm{n}^{\circ}$. - Fleurs retombant d'un vase, fond foncé.

Sans $n^{\circ}$. - Guirlande de fleurs en cercle, autour d'un motif central, fond blanc.

Sans $\mathbf{n}^{\circ}$. - Croix de Malte sur fond blanc avec, dans les quatre angles, des têtes d'anges.

No 1009. - Echiquier en velours.

No 26139. - Papillons et coquillages sur fond blanc.

Sans $\mathrm{n}^{\text {os }}$. - Deux tableaux d'oiseaux sur fond blanc. 
54 GASPARD GRÉGOIRE ET SES VELOURS D'ART

$$
M^{\text {me }} \text { Alice } J_{\text {APy }} \text { possède : }
$$

Un portrait de Bonaparte, Premier Consul, en pied, œuvre parfaite d'exécution.

$$
\text { L'AUTEur possède: }
$$

Un sujet d'après la IV ${ }^{\mathrm{e}}$ Heure du jour de Raphaël : femme drapée à l'antique, tenant un cadran solaire ; traité dans des tons camaïeux, rose sur fond noir ; rectangulaire, environ $0,22 \times 0,30$.

Tête de femme couronnée de roses, médaillon rond, diamètre environ $0,61 / 2$.

Episode de bataille, médaillon ovale, envir on $0,12 \times 0,10$. 


\section{LES IMITATEURS DE GREGOIRE}

Au premier rang de ceux-ci, nous avons indiqué M. Spoerlin, de Vienne, d'après le Dictionnaire des Tissus, de Bezon, sans pouvoir porter d'appréciation sur ses essais.

Nous nommerons encore :

Herguez, vieux dessinateur de fabrique. de Lyon, vers 1850 ou plus tard, qui a fait, paraît-il, un saint Jean Báptiste, médaillon ovale, et in portrait de femme ; ces deux essais ne sortant pas de la médiocrité.

M. Garin, de Lyon, ancien dessinateur de fabrique, qui a exécuté d'abord dans la manière noire, imitation de gravure, de petits sujets : portrait de la Princesse de Lamballe, portrait de femme du Second Empire, etc., qui ne sont pas dénués de mérite sous le rapport composition et exécution.

Il a fait beaucoup mieux encore avec les deux petits tableaux de fleurs qui sont au Musée de Lyon, celui surtout du verre d'eau avec les roses; ces deux compositions sont assez parfaitement réussies et proportionnées comme étoffe, peinture, etc., pour qu'on puisse les considérer comme se rapprochant de près des velours authentiques de Grégoire, quoique, à l'examen, le type de leur dessin et leur coloris les classent indubitablement en dehors et à l'époque bien postérieare de leur production.

M. Henry, le fabricant lyonnais réputé de tant d'étoffes remarquables, véritables œuvres d'art, a tenté également une reconstitution du procédé Grégoire; le sujet obtenu dans ce genre, Heure de Raphaël, qu'il avait exposé encore à Galliera en 1906, atteste la réelle difficulté que comporte pareille tentative; les proportions sont respectées oulà peu près, lle nué est terne avec des tons qui seperdent et 
paraissent décolorés; l'ensemble ne donne pas l'effet des œuvres imitées.

En 1894, lors de l'Exposition de Lyon, M. Martin, alors plieur pour la fabrique, tira parti de ses connaissances techniques, avec le concours de dessinateurs expérimentés, pour un nouvel essai dont les résultats parurent à cette Exposition ; il avait fait: un Amour d'après Boucher, dont un exemplaire se trouveau Musée des Tissus deLyon ; - une Bergère Louis XV ; - un Christ d'après Flandrin. - Il nous a confirmé lui-même, en nous donnant fort obligeamment des détails sur la marche suivie par lui pour la peinture et le tissage, identique à celle que nous avons exposée, combien il est peu facile d'obtenir un bon résultat et l'ingratitude de ce travail.

Enfin il nous semblerait injuste de ne pas noter l'intéressante imitation des velours Grégoire obtenue par l'impression sur chaîne, mode d'impression qui a du reste complètement remplacé le chiné, en usant de dessins étudiés dans ce but et pour chaque couleur, de planches, gravées en conséquence, soit de cinq à sept fois plus longues selon le retrait du velours au tissage qu'elles ne le seraient pour une impression ordinaire, tout en n'étant pas plus larges que d'habitude; le tissage du velours remet ensuite le dessin dans ses proportions. On a exécuté de cette manière réellement pratique et industrielle chez des imprimeurs habiles, tels que BrunetLecomte à Jallieu, des choses remarquables. Toutefois la planche, quelque habilement combinée et appliquée qu'elle soit, ne peut donner à beaucoup près les finesses du pinceau, ses demi-teintes, ses ombrés, ses fondus, ses contours souples, adoucis, déliés, respectant la ligne du modèle, ni communiquer à l'ouvre comme un caractère de personnalité ; ces impressions ne sont donc pas de véritables velours Grégoire.

Celui-ci, jusqu’à ce que des imitateurs nouveaux de sa patience, de son ingéniosité, de son talent, aient tenté de marcher avec plus de succès sur ses traces, peut-être en utilisant les moyens de plus en plus nombreux dont dispose la décoration moderne, reste bien le maître incontestable 
de l'art subtil qu'il avait créé. Nous voudrions pouvoir penser, qu'essayer de rendre à son mérite, peut-être trop ignoré, tout ce qui lui est dû de juste admiration, n'était pas œuvre inutile, sans intérêt, et trop au-dessus du but de cette courte étude. 


\section{PIÈCES JUSTIFICATIVES}

$\mathrm{N}^{\circ}$ 1. Acte de baptême.

Gaspard Grégoire, fils de M. Gaspard Grégoire, marchand, et de dame Thérèse Berrages, mariés, est né et a été baptisé ce jourd'huy, vingt octobre 175 (sic) (1751). Le parrain a été M. Gaspard Grégoire, son aieul paternel, et la marraine dame Thérèse Boyer-Carnaud, signés avec nous. Boyer-Carnaud, Grégoire, Bẻrage, Grégoire, Boyer fils, Vocanson, vicaire.

(Arch. municipales d'Aix en Provence, HH 63.) (Registres des baptêmes, mariages et sépultures de la paroisse Sainte-Madeleine, année 1751)

№ 2. Assemblée générale convoquée par MM. Batalier et

Thumin, syndics en exercice et tenue dans la chapelle de Saint-Joseph à l'Oratoire.

Le quatre du présent mois de juin 1777, M. Batalier, premier syndic portant la parole, a dit qu'il avait été visité de la part de Messieurs Louis-Denis Grégoire, Gaspard Grégoire et Dominique-Alexandre Grégoire, lesquels les auraient priés de vouloir bien les proposer à l'Assemblée du Corps pour y être reçus Maitre en qualité de fils de Maitre, conformément aux statuts.

Sur quoi l'Assemblée, après avoir pris connaissance de leur religion, vie, mœurs et capacité, a délibéré à l'unanimité des suffrages de recevoir Messieurs Louis-Denis Grégoire, Gaspard Grégoire et Dominique-Alexandre Grégoire dans le Corps et communauté de marchand en qualité de fils de Maître à l'effet de jouir par eux de tous les droits, honneurs et prérogatives y attachés et plus n'a été délibéré ; à Aix, le 4 juin 1777. 
Signé : Batalier, Thumin, syndics, etc.

Et Grégoire cadet, Dominique Grégoire, Grégoire aîné.

(Archives d'Aix. - Marchands d'Aix - HH. 63, folios 196 et 97.)

No 3. Archives nationales Oı 1674. Maison du Roi.

\section{Monsieur le Comte,}

Paris, 5 septembre 1785.

La nécessité qui oblige $M$. Grégoire à vous demander la suppression du dernier plancher au Logement que vous lui avez accordez aux Galleries du Louvre me parait fondé relativement à l'établissement de métiers, qu'il doit faire dans le $\mathrm{d}^{t}$ logement et en conséquence de la hauteur dont il a besoin, celle de l'étage qu'il a préféré ne suffit pas pour les placer.

J'ai examiné par votre ordre si la suppression de ce plancher pouvait se faire sans inconvénient, et c'est après avoir observé que le $d^{t}$ plancher de charpente est construit sur des lambourdes soutenues par des corbeaux de fer scellés dans le mur, qu'on peut le démolir sans préjudicier à la construction du Lieu. Néanmoins, je crois convenable de contraindre M. Grégoire à conserver l'escalier dans toute sa hauteur, ainsi que le tambour ou cage qui le renferme.

$1^{\circ}$ Parce que cette cage est trop pettite pour nuire à la dimension de la pièce.

$2^{\circ} \mathrm{Si} \mathrm{M}$. Grégoire quittait ce logement et que la personne qui le remplacerait demanda que ce plancher soit rétablie, alors il couterait (illisible) que l'escalier aura été conservé et que dans tous les cas (excepté dans celui-ci) un étage de plus sera toujours commode et indispensable pour i pratiquer des Logements de domestiques.

Monsieur Grégoire vous prie de l'honorer d'une prompte réponse afin que les ouvriers qu'il a fait venir de Lion puissent travailler très incessamment aux objets que vous lui avec confiez.

Je suis avec un profond respect

Votre très humble et très soumis serviteur

Monsieur le Comte,

Renard. 
N`4. Archives nationales Oı 1919, p. 5. Beaux-Arts, Maison du Roi.

M. C.

22 août 1786 .

\section{AFFAIRES GÉNÉRALES}

Le Sieur Grégoire ayant le secret de peindre en velours demande une somme ou subvention, (mot illisible) de 3.000 livres à titre d'encouragement et pour être employée à des essais en grand.

\section{MÉMOIRE.}

Le Sieur Grégoire a eu l'honneur de présenter ses premiers essais en velours à M. le comte d'Angiviller qui a daignéles accueillir avec bonté; il aurait dû sans doute s'assurer auparavant de pouvoir exécuter des objets en grand comme les seuls qui puissent intéresser M. le Comte, mais le Sieur Grégoire n'étant pas fabriquant, il n'a eu la permission de travailler nulle part; c'est cette permission qu'il est venu solliciter à Paris; ce n'est même qu'après beaucoup de peines et d'épreuves qu'il a pu réussir à Lyon à exécuter ses petits essais.

Le Sieur Grégoire s'est engagé à l'exécution du portrait de la Reine et d'un tableau de fleurs sans promettre un entier succès; le portrait de la Reine a mal réussi, cela est vrai et le tableau de fleurs en conséquence n'a pas été exécuté, mais il avait l'espoir de réussir et surtout la certitude de faire ces ouvrages en petit, mieux qu'aucun autre de ces ouvrages; $M$. le Comte peut en juger d'après les copies qui sont entre ses mains.

C'est la première fois que le Sieur Grégoire a entrepris un ouvrage dans la largeur du velours ; le logement qu'il occupe n'étant pas disposé favorablement pour ses métiers, les opérations ont été pénibles et défectueuses, mais il est assuré du moins de pouvoir à l'avenir exécuter assez bien des ouvrages de cette grandeur, ce qui était incertain auparavant. Le Sieur Grégoire n'a cessé de faire des épreuves relatives à la perfection de ses ouvrages en velours; il peut faire en ce moment l'expérience intéressante qu'il a eu l'honneur de proposer depuis très peu de temps à M. le Comte 
et qu'il ne lui a point annoncée avant d'être assuré du succès. Si elle peut par cette raison lui donner quelque confiance pour d'autres recherches que le Sieur Grégoire a à faire, elle sera pour lui inappréciable.

L'ouvrage du Sieur Grégoire n'est pas comme ceux de toutes les manufactures dont les moyens assurés avant l'entreprise n'exigent plus qu'un travail de spéculation; il ne peut lui-même compter solidement sur quelques moyens qu'il a en vue qu'après une exécution dispendieuse. Il doit paroître juste du moins qu'il soit assuré d'en retirer le fruit en cas de réussite. Un travail exclusif et un terme un peu long sont les faveurs essentielles qui peuvent lui faire espérer d'en être dédommagé.

M. le Comte a la bonté de lui proposer un brevet pour (en blanc) ans. Le Sieur Grégoire l'acceptera avec reconnaissance, espérant qu'il sera accompagné des titres qui le mettent à l'abri de tous risques et que Sa Majesté voudra bien se réserver de lui accorder quelque autre grâce qui assure encore mieux son établissement quand il présentera des ouvrages qui auront plus de succès.

M. le Comte veut bien lui accorder pendant ces (en blanc) années la somme de 3.000 livres sous des conditions relatives aux objets en grand dont le secret appartiendrait au Roi, etc., etc. Il est naturel que le Sieur Grégoire désire la très grande faveur et le très grand avantage que ses ouvrages soient agréés par Sa Majesté. C'est dans cet espoir qu'il a présenté ses premiers essais à M. le Comte qui a augmenté cet espoir en jugeant qu'ils méritoient d'être protégés, mais il permettra au Sieur Grégoire de lui observer que ne sachant point encore à quoi il réussira, l'engagement le plus simple peut devenir pour lui très dangereux; aussi il espère que $M$. le Comte voudra bien lui accorder cette somme à titre d'encouragement et cependant pour être employée à des essais en grand.

Le Sieur Grégoire fera tous ses efforts pour mériter la continuation des bontés dont $\mathrm{M}$. le Comte a daigné lui donner des marques distinguées jusqu'à ce jour, il espère qu'elles ne seront point infructueuses. 
N०5. - Archives nationales $0^{1} 1919$, p. 5.

M. C.

8 août 1787.

\section{DÉPARTEMENT DES ARTS}

Le Sieur Grégoire, père de celui qui étudie et qui a avancé jusqu'à un certain savoirl'art d'exécuter des tableaux en velours, demande que les essais de son fils soient présentés au Roi.

Le même jour. Répondre en déduisant avec honnêteté et même complaisance les considérations qui combattent les vues de son fils sur ce qui est grâces à obtenir du gouvernement qui ne peut et ne doit en accorder qu'à des découvertes utiles et vérifiées.

\section{Monsieur le Comte,}

L'accueil favorable que vous avez fait à mon fils lorsqu'il a eu l'honneur de vous présenter son nouveau genre de tableaux en velours, la bonté que vous avez eue de lui accorder un logement aux Galeries du Louvre et de lui faire donner un encouragement en argent, l'éblouirent si fort qu'il se décida de quitter le commerce pour se livrer entièrement à ce travail et à des découvertes ultérieures, d'accord avec moi et toute ma famille qui heureusement ne fait qu'un tout.

Persuadé que ces ouvrages seraient présentés à Sa Majesté ainsi que vous l'avez toujours fait espérer à mon fils, j’en ai attendu la réussite pour n'avoir qu un remerciement à vous faire. Deux ans se sont écoulés, sans que j’aie eu cette flatteuse satisfaction.

J'ai la douleur d'apprendre aujourd hui, après ce long espace de temps et après les dépenses particulières que j’ai faites qui sont immenses (pour un père qui a huit enfants) que toutes ces espérances sont évanouies, au point que le logement de mon fils doit être occupé sous peu par M. Lagrenée.

Cela étant, Monsieur le Comte, que doit devenir ce cher fils, 
auquel je n'ai aucun reproche à faire ? Ses dépenses excessives étant de première nécessité pour sa nourriture et celle de son frère, celle des ouvriers qu'il a encore en grande partie, celles pour le prix des soies achetées à Lyon et en Piémont, des métiers, des petits meubles et généralement pour l'entretien le plus simple, etc., etc.

Je ne peux pas douter, Monsieur le Comte, de la beauté des ouvrages de mon fils, par l'estime que vous en avez faite vous-même, par celle de M. 'Boutin, du Conseil royal des Finances, de M. le Comte de Thiers, du fils de M. de Miromesnil, de presque tous les membres du Parlement et de la Cour des comptes de Provence, et généralement par l'approbation de tous les amateurs d'Aix, de Marseille, de la Province et d'un nombre infini de seigneurs Anglais qui me sont tous adressés par tant de maisons de banque, etc. On n'en a même vu que les premiers essais qui ont été admirés par toutes ces personnes si recommandables qui sont venues les voir chez moi.

J'ai voulu que mon heureuse famille, mon fils et moi ne dussions qu à yous seul, Monsieur le Comte, la jouissance de ces découvertes inattendues, fruits du génie, de l'application et de l'éducation la plus soignée. La pius grande grâce que nous demandions est que les ouvrages soient présentés par vous à notre souverain; nous vous supplions de nous l'accorder ; l'accueil qu'il recevront décidera ensuite d'un privilège qui ne pourra jamais choquer en rien les manufactures royales ni celles de Lyon, puisqu'il n'y sera jamais question que d'ouvrages en velours de médiocre grandeur.

Ces découvertes utiles et j'ose dire admirables, appartiennent en propre à mon fils, vous trouverez juste, M. le Comte qu'il en jouisse pendant quelques années comme étant son propre bien. Elles seraient perdues pour la société si ce cher enfant venait à mourir.

Vous êtes le protecteur né des Arts, et je ne saurais trop vous assurer du profond respect avec lequel je suis

Votre très humble et très obẻissant serviteur,

GréGolre PÈre.

A Aix, le 31 juillet 1787. 
No 6. - Archives nationales 0 1919, p. 5.

M. C.

7 novembre 1787 .

\section{DÉPARTEMENT DES ARTS}

Le Sieur Grégoire fils, inventeur de tableaux sur velours, demande un privilège exclusif et un dédommage ment de ses dépesises et de son tems.

A M. le Comte de la Billardrie d'Angiviller, directeur et ordonnateur général des Bàtimens du Roi, etc., etc.

\section{Monsieur le Comte,}

Mon père m'a fait part de la lettre que vous avez bien voulu lui écrire en réponse à celle qu'il a eu l'honneur de vous adresser. Je vois que vous ètes toujours dans les mêmes idées relativement à mes petits ouvrages, que vous ne croyez pas susceptibles de donner lieu à une spéculation avantageuse. Il est vrai que je ne sais pas jusqu'à quel point je réussirai à en adoucir le prix, mais quoi qu'il en puisse être, je suis assuré qu'il sera toujours très modéré et je désire très fort d'en courir le risque.

Quant aux objets en grand qui sont les seuls qui vous intéressent, vous êtes trop persuadé que l'on ne doit pas y compter; cependant j'ai lieu de croire que je pcurrai exécuter des sujets de fleurs pour meubles et copier des tableaux dans la largeur du velours; je suis assez assuré pour pouvoir le promettre. Les essais que vous m'avez ordonné de faire vous ont fait oublier cet espoir quoiqu'il soit augmenté pour moi.

Quand j'ai eu l'honneur de vous présenter mes premiers ouvrages, j’aurois désiré d'obtenir un privilège exclusif pour les moyens nouveaux dont je suis l'inventeur, j'etois assuré de l'exécution des petits objets en attendant de pouvoir pousser plus loin mes recherches; mais vous m'avez toujours proposé de faire des ouvrages en plus grand et enfin malgré 
le doute où j'étois de réussir, je me suis engagé à les entreprendre et vous avez bien voulu consentir que ce fût sans répondre du plus ou moins de perlection.

Le portrait de la Reine est mal exécuté, cela est vrai ; les dispositions du logement que j'ai occupé aux Galleries du Louvre ne m'ont pas permis de faire commodément toutes mes opérations, ce qui a contribué à les rendre pénibles et défectueuses, et quoique je n'aie pas assuré le succès de l'ouvrage, cela est d'autant plus fâcheux pour moi que je suis beaucoup plus certain que je n'étois de pouvoir réussir à l'avenir. J'ai exécuté en petit ce même portrait de la Reine et des tableaux de fleurs ; vous avez été plus satisfait de ces nouveaux ouvrages que des premiers essais que j'ai faits. Il y a bien longtemps quej'ai eu l'honneur de vous les remettre; vous m’avez fait espérer qu'ils seroient présentés toutes les fois quevous $m$ 'avez permis de vous le rappeler, et cependant j'ai reçu un ordre de votre part le 30 juillet pour quitter les Galleries du Louvre avant qu'il y eût aucune décision, de sorte que depuis ce tems, je suis sans état avec des ouvriers à nourrir.

Quand je me suis engagé d'entreprendre des ouvrages difficiles, j'ai dû calculer mon temps et mes dépenses, mais je n'ai pas dù croire que j'aurois à attendre encore à ce moment une décision sur mon établissement; ma fortune ne peut résister à de pareilles épreuves, mais j'espère de votre justice que vous voudrez bien m'accorder un dédommagement pour le temps et les dépenses que j’ai employées depuis plus de seize mois que j'ai eu l'homneur de vous remettre mes ouvrages. Il est bien malheureux pour moi d'avoir dépensé vingt mille livres depuis que j'ai quitté ma famille et mon commerce, sans avoir obtenu la permission de travailler et d'être encore dans l'incertitude de savoir si je pourrai faire état de ma découverte et si l'on m'en accordera la propriété par un privilège.

Vous n'avez pas oublié sans doute, Monsieur le Comte, que j'ai eu l'honneur de vous dire il y a plus de deux ans que j'avois trouvé une méthode pour noter les couleurs et que depuis ce tems, ayant trouvé le moyen de pouvoir exécuter 
sur un métier monté en velours la couleur qui me sera demandée je vous ai proposé d'en faire l'expérience. Je n’attends plus que le moment de pouvoir donner une application utile à ces découvertes.

J'espère de vos bontés que vous voudrez bien terminer au plus tòt les embarras où je suis par les dépenses et les pertes de tems que j'éprouve, et que vous voudrez bien contribuer à me faire obtenir des conditions favorables.

Je suis avec un profond respect de M. le Comte

Le très humble et très obéissant serviteur,

G. Grégolre.

A Paris, le 13 septembre 1787.

No 7. - Archives nationales. F. 31, $\mathrm{n}^{\circ} 60$.

12 juillet 1788 .

Arrêt qui permet au Sieur Grégoire d établir une manufacture pour y exécuter en velours ou antres étoffes de soye suivant son procédé tontes sortes de tableaux représentant des figures, des fleurs et des animaux et autres objets semblables et lui accorde à cet effet un privilège exclusif de 15 années.

Sur la requête présentée au Roi en son conseil par le Sieur Grégoire, contenant qu'il a fait la découverte d'un procédé pảr lequel il exécute toutes sortes d'ouvrages en velours imitant la peinture. Les échantillons quil a produits, et qui ne laissent rien à désirer tant par la beauté et la variété des couleurs que pour la justesse des traits, ayant été défilés et examinés, il a été reconnu que les sujets n'étaient ni peints ni appliqués surle velours d'aucune manière que ce puisse être, mais qu'ils sont faits en fabricant l'étoffe. Le supliant s'engage à communiquer son procédé et à prouver que les opérations essentielles qui font seules le mérite de la découverte, tant par la célérité et la perfection des travaux que par le bas prix de l'ouvrage n'appartiennent à aucune méthode connue, mais à des principes nouveaux; qu'enfin cette invention est du nombre des découvertes les plus heureuses et qu'elle doit être comptée parmi celles qui tiennent le premier rang dans les manufactures. Le supliant s'oblige 
encore à perfectionner sa découverte et il se propose de former un établissement pour l'exécution de ses ouvrages. Mais comme les essais qu'il a été obligé de faire pour la perfection de son procédé lui ont occasionné des dépenses très considérables et qu'il ne pourrait jouir du fruit de sa découverte s'il étoit permis à tout autre defaire usage du procédé dont il est l'inventeur, il espère que le gouvernement voudra bien venir à son secours, en lui accordant un privilège exclusif pendant un certain nombre d'années, ainsi que quelques droits et une somme en espèces par forme de dédommagement.

Requérait à ces causes et le sup ${ }^{t}$ qu'il plùt à S. M. lui permettre d'établir soit à Paris, soit dans tel endroit du royaume qu'il jugera à propos, une manufacture pour y exécuter en velours ou autre étoffe de soye, suivantson procédé, toutes sortes de tableaux représentant desfigures, desfleurs et des animaux, ainsi que des écrans et autres objets semblables qui ne seront point en concurence avec les étoffes de soye de consommation ordinaire, lui accorder à cet effet un privilège exclusif, pendant le tems et espace de quinze années consécutives, fait défenses à toutes personnes de quelque qualité et condition qu'elles soient d'user pendant le $\mathrm{d}$. tems du procédé du supliant pour exécuter aucuns ouvrages que ce puisse être, à peine de saisie et confiscation desd. ouvrages et à tous dépens, dommages et intérêts ; fait pareillement défenses à tous corps et communautés de troubler et inquiéter le sup dans la fabrication, vente et débit des dits ouvrages, à peine aussi de tous dépens, dommages et intérêts; ordonner que ses ouvrages par lui représentés, pourront circuler librement dans tout le Royaume et être exportés à l'étranger sans payer aucuns droits; lui accorder par forme de dédommagement des dépenses par lui faites une somme de 30.000 livres dont 10.000 payables la première année et les autres dans les quatre années suivantes à raison de 5.000 livres par an. Lu la dite requête, l'avis des députés au Bureau du commerce du 27 mai dernier et les observations du $\mathrm{S}$. Desmarets, Inspecteur général directeur des manufactures, ensemble l'avis du Bureau du commerce, ouï le raport 
du $\mathrm{S}^{\mathrm{r}}$ Lambert, conseiller d'Etat et ordinaire au Conseil roïal des finances et du commerce, contrôleur gén ${ }^{1}$ des finances.

Le Roi en son conseil, ayant aucunement égard à la dite requête, a permis et permet au S. Grégoire d'établir, soit à Paris, soit dans tel autre endroit du roïaume qu'il jugera à propos, une manufacture pour y exécuter en velours ou autres étoffes de soye suivant son procédé, toutes sortes de tableaux représentant des figures, des fleurs et des animaux, ainsi que des écrans et autres objets semblables ; lui accorde à cet effet un privilège exclusif pendant le tems et l'espace des quinze années consécutives, sans néanmoins que sur le fondement $\mathrm{du} d$. privilège, il puisse empêcher la fabrication d'étoffes de soye faites et fabriquées dans des procédés autres que ceux de son invention et en conséquence fait S. M. très expresse inhibition et défenses à tous fabricans et à toutes autres personnes de quelque qualité et condition qu'elles soient de faire usage pendant le dit tems dudit procédé à peine de saisie et confiscation des dits ouvrages et de tous dépens dommages et intérêts, fait pareillement défenses à tous corps et communautés de troubler et inquiéter le sup ${ }^{t}$ dans la fabrication, vente et débit de ses ouvrages, à peine aussi de tous dépens, dommages et intérêts.

Ordonne S. M. que les ouvrages par lui exécutés pourront circuler librement dans tout le Royaume sans payer aucuns droits et qu'à l'égard de ceux qui seront exportés à l'étranger, ils seront assujettis à un droit de sortie de dix sols pour chacun d'eux.

Ordonne en outre S. M. que des fonds à ce destinés, il sera payé au supt par forme de dédommagement des dépenses une somme de 12.000 livres en 2 termes de 3 mois en 3 mois, après qu'il aura été constaté que son procédé est différent de la Tire et du Chiné et que les sujets ne sont pas peints sur le velours, à l'effet de quoi, il sera tenu d'exécuter en présence des $S^{\text {is }}$ Desmarets et Abeille, Inspecteurs généraux des manufactures et du commerce, la fabrication de ses ouvrages et de donner par écrit son procédé dont une copie sera déposée entre les mains du S. Desmarets 
et une autre au $B^{\text {eau }}$ de l'Administ ${ }^{\text {on }}$ du Commerce, pour le dit procédé être rendu public à l'expiration des quinze années. Et seront sur le présent arrêt si besoin est, toutes lettres patentes expédiées.

No 8. - Archives nationales F. 12-999-1001.

Au Ministre de l'Intérieur.

\section{Citoyen Ministre,}

Le citoyen Gaspard Grégoire, né à Aix, département des Bouches-du-Rhòne, artiste fabriquant à métiers, patenté pour l'an 8 sous le $n^{\circ} 144$, demeurant rue Paradis, $n^{\circ} 20$, division Poissonnière, à Paris.

Vous Expose,

Qu'il désire jouir du droit de propriété assuré par les lois des 7 janvier et 25 mai (vieux style) aux auteurs des découvertes et inventions en tous genres d'industrie et en conséquence obtenir un brevet d'invention qui durera l'espace de 15 ans, pour fabriquer, vendre et débiter exclusivement dans toute l'étendue de la République des étoffes ou tissus circulaires, plans et autres formes à lisières on à fonds inégaux qu'il nomme Tournoises, les dites étoffes applicables à beaucoup d'objets, principalement de parure et ornements pour hommes et pour femmes, de même que pour meubles, dont je déclare êtrel'inventeur et dont les moyens d'exécution et procédés sont exprimés sur les plans et mémoires exécutifs ci-joints, accompagnés d'échantillons provenant de la dite fabrication et ce, en remplissant les formalités prescrites et acquittant la taxe et les droits fixés dans la loi réglementaire du 25 mai 1791 (vieux style).

Paris, ce troisième jour complémentaire de l'an huit de la République.

G. GrÉGOIRE. 
No 145.

(Gouverture)

\section{BREVET D'INVENTION}

POUR 15 ANs.

Le $\mathrm{C}^{\mathrm{n}}$ Gaspard Grégoire, auteur d'une machine propre à fabriquer des étoffes ou tissus circulaires qu'il nomme Tournoises.

Dẻlivrẻ le 2 nivôse an 9.

$N^{\circ} 145$.

Le $\mathrm{C}^{\mathrm{n}}$ Gaspard Grégoire demande un certificat d'additions et perfectionnement à la fabrication des Tournoises pour laquelle il a été breveté le 2 nivôse an 9, pour 15 ans.

Attestation dèlivrée le 22 ventôse an $\mathbf{1 0}$.

Brevet d'invention établi par la loi du 7 janvier 1791 .

Attestation de demande d'un certificat de perfectionnement.

Le Ministre de l'Intérieur,

Chaptal.

No 9. - Archives nationales AF IV, Section moderne.

\section{MINISTĖRE DE L'INTÉRIEUR}

MINUTE D'ARRÊTÉ.

Proclamation des brevets d'invention délivrés pendant les mois nivôse, pluviôse et ventôse an $9^{e}$.

Paris le 22 prairial an $9^{\text {e }}$ de la République une et indivisible.

Les consuls de la République, sur le rapport du Ministre de l'Intérieur.

Vu l'article 6 du titre Ir de la loi du 25 may 1791 ,

Vu pareillement l'article $1^{\text {er }}$ de l'arrêté du $\overline{5}$ vendémiaire 
$\mathrm{d}^{\circ}$, portant que les brevets d'invention, perfectionnement et importation seront délivrés dans les trois mois et promulgués ensuite, par la voie de l'insertion au Bulletin des Lois.

Arrêtent que les citoyens ci-après dénommés sont définitivement brévetés et que les articles suivant seront insérés dans le plus prochain numéro du Bulletin des Lois.

\section{ARTICLE I Ier.}

Le 2 nivôse de l'an 9, il a été délivré par le Ministre de l'Intérieur un certificat de demande d'un brevet d'invention pour 15 années au citoyen Gaspard Grégoire, artiste fabricant, demeurant à Paris, rue de Paradis, $\mathrm{n}^{\circ} 20$, pour des étoffes ou tissus circulaires, plans et autres formes à lisières ou à fonds inégaux qu'il nomme Tournoises.

\section{Le premier Consul, Bonaparte.}

No 10. - Archives nationales F. 13-910.

Paris, ce 5 nivôse an XII.

Au Ministre de l'Intérieur.

\section{Citoyen Ministre,}

Vous m'avez fait espérer que vous agrandiriez le local que vous avez accordé à l'Etablissement des velours; vous vous rappellerez de même la disposition où vous étiés d'accorder les réparations nécessaires dont quelques-unes sont très urgentes.

En conséquence je vous prie :

$1^{\circ}$ De vouloir bien nommer un architecte au plutôt, pour faire les devis des réparations de première nécessité.

$2^{\circ}$ (Illisible) régler la division du logement avec le citoyen Mille qui occupe la partie droite de l'hôtel Vaucanson ; observant que la rotonde du milieu du bâtiment est indis- 
pensable pour les opérations du velours et que d'ailleurs il y a deux entrées au jardin, l'une du côté occupé - par le citoyen Mille, l'autre par cette rotonde, de sorte que si le citoyen Mille conservait cette rotonde, il aurait seul les deux entrées. Les citoyens Lancel et Morry qui ont vue sur le local, pourront vous confirmer la nécessité et l'utilité de ces deux objets.

Je vous salue avec respect,

\section{G. Grégolre.}

$N^{*}$ 11. - Archives départementales de la Seine.

Rôle 1251 .

ACTE DE DÉCE்s.

Grégoire Gaspard, né à Aix (B.-du-R.), exerçant la profession de mécanicien, célibataire, décédé à Paris le 12 mai 1846 à l'âge de quatre-vingt-quatorze ans en son domicile, rue de Charonne, $\mathrm{n}^{\circ} 47$ ( $8^{\mathrm{e}}$ arrondissement), fils de Grégoire et dé femme Grégoire née Berrages.

Ponr rester dans le cadre de ce travail, nons nous somnes borné à reproduire, parmi toutes celles retrouvées, les quelques pièces qui nous ont paru les plus importantes. - Note de l'auteur. 










$$
\left(\begin{array}{ccc} 
& 591 & \\
0 & & 503 \\
0 & \text { Dekatt Ave. } & 0
\end{array}\right)
$$


